\title{
Measuring Water Flow Rate for a Fire Hose Using Wired Accelerometers for Smart Fire Fighting
}

Christopher U. Brown Gregory W. Vogl Wai Cheong Tam 


\title{
Measuring Water Flow Rate for a Fire Hose Using Wired Accelerometers for Smart Fire Fighting
}

\author{
Christopher U. Brown \\ Wai Cheong Tam \\ Fire Research Division \\ Engineering Laboratory \\ Gregory W. Vogl \\ Intelligent Systems Division \\ Engineering Laboratory
}

This publication is available free of charge from: https://doi.org/10.6028/NIST.TN.2075

November 2019

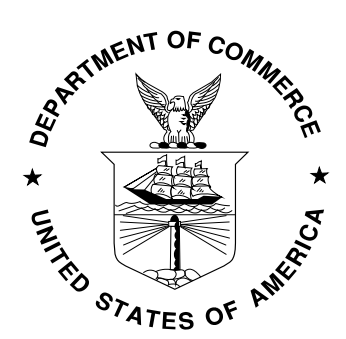

U.S. Department of Commerce Wilbur L. Ross, Jr., Secretary

National Institute of Standards and Technology Walter Copan, NIST Director and Undersecretary of Commerce for Standards and Technology 
Certain commercial entities, equipment, or materials may be identified in this document in order to describe an experimental procedure or concept adequately. Such identification is not intended to imply recommendation or endorsement by the National Institute of Standards and Technology, nor is it intended to imply that the entities, materials, or equipment are necessarily the best available for the purpose.

The opinions, recommendations, findings, and conclusions in this publication do not necessarily reflect the views or policies of NIST or the United States Government.

National Institute of Standards and Technology Technical Note 2075 Natl. Inst. Stand. Technol. Tech. Note 2075, 36 pages (November 2019) CODEN: NTNOEF

This publication is available free of charge from: https://doi.org/10.6028/NIST.TN.2075 


\begin{abstract}
A wired sensor network was created to measure water-flow rate in a fire hose. An integrated electronic piezoelectric (IEPE) accelerometer was chosen as the sensor to measure the flow rate based on the vibrations generated by water flowing through a fire hose. These sensors are small, lightweight, and they can be attached to the outside of the hose, not obstructing the water's flow path. A relationship was determined between the flow rate of the water and vibration detected by the accelerometer for a range of flow rates. The raw acceleration signal was used to calculate two metrics: the dominant frequency and the standard deviation of acceleration. In a future study, the relationship between the dominant-frequency metric and the flow rate will be applied to a wireless accelerometer network. The relationship will be used to determine the real-time fire hose flow rate critical for improving situational awareness on the fireground.
\end{abstract}

\title{
Keywords
}

Accelerometers; fire hose; flow induced vibration; flow rate; hose vibration; dominant frequency; smart fire fighting; sensors; water flow rate measurement; wired sensor network. 


\section{Table of Contents}

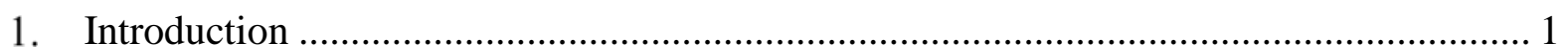

1.1. Smart Fire Fighting - Water Flow at the Fire Hose Nozzle................................... 1

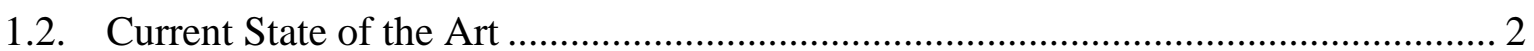

1.3. Normal pump pressure, but low nozzle flow due to hose rupture or leak.................. 3

1.4. Normal pump pressure, but low nozzle flow due to blockage ................................. 4

1.5. Study Goal ...................................................................................................... 5

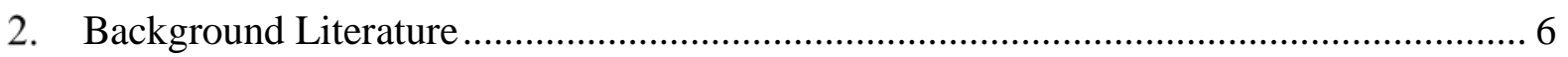

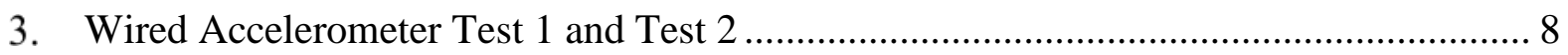

3.1. Introduction - Wired Accelerometer Test 1 and Test 2 ....................................... 8

3.2. Methods - Wired Accelerometer Test 1 and Test 2.............................................. 8

3.3. Results and Discussion - Wired Accelerometer Test 1 and Test 2 ........................ 12

3.3.1. Results and Discussion - Wired Accelerometer Test 1 ................................... 14

3.3.2. Results and Discussion - Wired Accelerometer Test 2 ................................... 15

4. Wired Accelerometers Test 3 - Four Accelerometer Study .......................................... 16

4.1. Introduction - Wired Accelerometers Test 3 ................................................... 16

4.2. Methods - Wired Accelerometers Test 3........................................................... 16

4.3. Results and Discussion - Wired Accelerometers Test 3...................................... 20

4.3.1. Results and Discussion - Wired Accelerometers Test 3 - Standard Deviation of

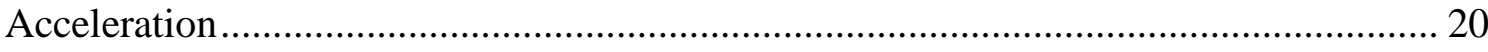

4.3.2. Results and Discussion - Wired Accelerometers Test 3 - Dominant Frequency 23

5. Practical Considerations for a Nozzle Flow Meter.................................................. 26

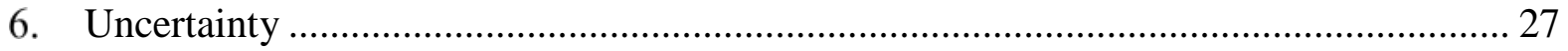

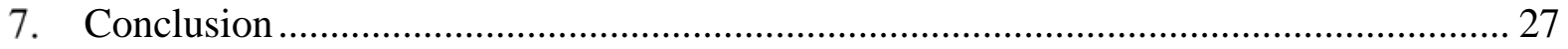

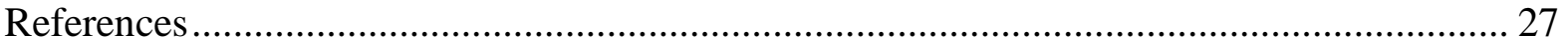




\section{List of Figures}

Fig. 1. A smart sensor network can measure flow rate at the fire hose nozzle and wirelessly transmit the flow rate to the IC and pump operator for decision making.

Fig. 2. Threats to normal nozzle flow include holes from wear and tear or burns, leaking couplings, or hose rupture from car tires or structural collapse.

Fig. 3. Normal water flow at the hose nozzle is reduced by a partially blocked hose from crimping or pinching, or a fully blocked hose from a closed valve or closed nozzle bale, yet these dangerous conditions may not be obvious at the pump panel where water pressure may appear normal.

Fig. 4. The transducer base was epoxied to the hose fabric and the accelerometer was screwed tightly to the base. Black electrical tape was applied to provide additional support to the transducer while the epoxy cured.

Fig. 5. The transducer was attached to the hose approximately $31 \mathrm{~cm}$ (12 in) downstream from the hose-water source attachment point. Black electrical tape was applied to help provide stress relief to the wire leads from the transducer.

Fig. 6. The in-line turbine flow meter and dial pressure gauge at the nozzle end of the hose during testing.

Fig. 7. The wired experiment set up during data collection. The force and acceleration lead wires from the transducer were attached to the DAS and the laptop.

Fig. 8. The impact hammer was used on the force sensor of the transducer. ........................ 11

Fig. 9. The flow rate was adjusted for each setting using the nozzle while reading the in-line turbine flow meter.

Fig. 10. A sample of raw acceleration data from an accelerometer during a flow test (379 LPM (100 GPM)) for a 0.3-second-long time period. The standard deviation of the acceleration signal is used as a metric.

Fig. 11. A sample of the dominant frequency based on the power spectrum. A peak can be seen around $300 \mathrm{~Hz}$.

Fig. 12. Standard deviation of acceleration versus flow rate for Test 1. A peak is noted around 344 LPM (91 GPM).

Fig. 13. Standard deviation of acceleration versus flow rate for Test 2.

Fig. 14. The two accelerometers at the upstream (Back) location (on the concrete floor (left), and the downstream (Front) location outside in the grass close to the nozzle (right)........... 16

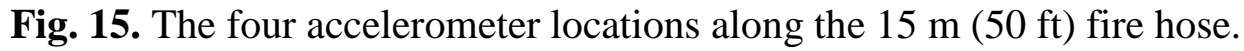

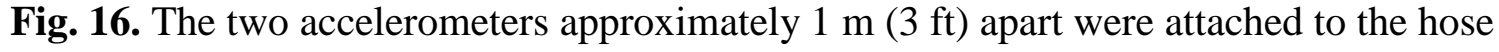
resting on the concrete floor.

Fig. 17. Nozzle, dial pressure gauge, and turbine flow meter at the downstream (Front) end of the fire hose.

Fig. 18. The fire hose attached to the building water source and three accelerometers on the floor (left), and the downstream (Front) accelerometer in the grass and the nozzle (right)... 18 Fig. 19. Impact testing on the downstream (Front) accelerometer using the rubber-tipped impact hammer.

Fig. 20. The standard deviation of acceleration versus flow rate for the accelerometer in the upstream (Back) location.

Fig. 21. The standard deviation of acceleration versus flow rate for the accelerometer in the downstream (Front) location, closest to the nozzle. 
Fig. 22. The standard deviation of acceleration versus flow rate for the accelerometer in the middle upstream (Mid-Back) location. ....................................................................... 21 Fig. 23. The standard deviation of acceleration versus flow rate for the accelerometer in the middle downstream (Mid-Front) location.................................................................... 21 Fig. 24. Typical results of the standard deviation of acceleration versus flow rate for the four

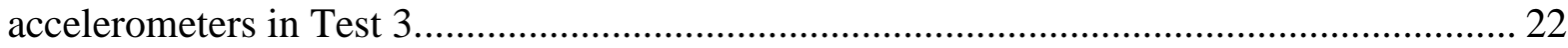

Fig. 25. Dominant frequency versus flow rate for all four accelerometers for Test 3........... 23 Fig. 26. The mean and standard deviation for the dominant frequency versus flow rate for the Front accelerometer for all 50 data collection increments for Test 3.

Fig. 27. Dominant frequency versus flow rate for the Front accelerometer for Test 3 as determined by impact testing. 25 Fig. 28. Mean dominant frequency versus flow rate for the Front accelerometer for Test 3 as

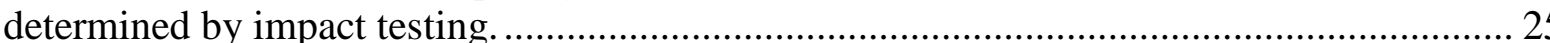




\section{Introduction}

\subsection{Smart Fire Fighting - Water Flow at the Fire Hose Nozzle}

There is an old fire service saying, "As the first line goes, so goes the fire.” Placing and flowing water through initial, intermediate, and final hose lines is very important for the success of a fire attack. The water discharged from the hose nozzle cools the environment, which improves the survival of trapped occupants, protects the fire fighters from excessive heat, and extinguishes the fire. Therefore, hoses are simultaneously a fire fighter's and occupant's lifelines [1]. Knowing the water flow rate through a fire hose is a critical part of fire suppression and situational awareness, especially for zero flow conditions, which are not uncommon.

Applying 'smart' technology to a fire hose could improve 1) the awareness of the hose's current status and 2) the chance of a successful fire attack. Harnessing the power of 'smart' technology to improve situational awareness of the hoses was a part of the vision of Smart Fire Fighting as documented in the Research Roadmap for Smart Fire Fighting [2]. A 'smart' system uses sensors to collect data, provides the data in an understandable format to a user, then allows the user to make decisions. Today, the users are humans, but tomorrow they may include software.

Human fire fighters are the backbone of the fire service. The safety of fire fighters who risk their lives on the fireground could benefit from a smart sensor network that could perform two tasks: determine if water is flowing at the fire-hose nozzle and communicate this information back to a human controller at the fire engine. The smart system includes a sensor at the nozzle, wirelessly communicating the flow rate data to the incident commander (IC), and a way to present the data to the IC (Fig. 1). The IC must be able to make quick decisions regarding the water flow for suppression activities on the fireground.
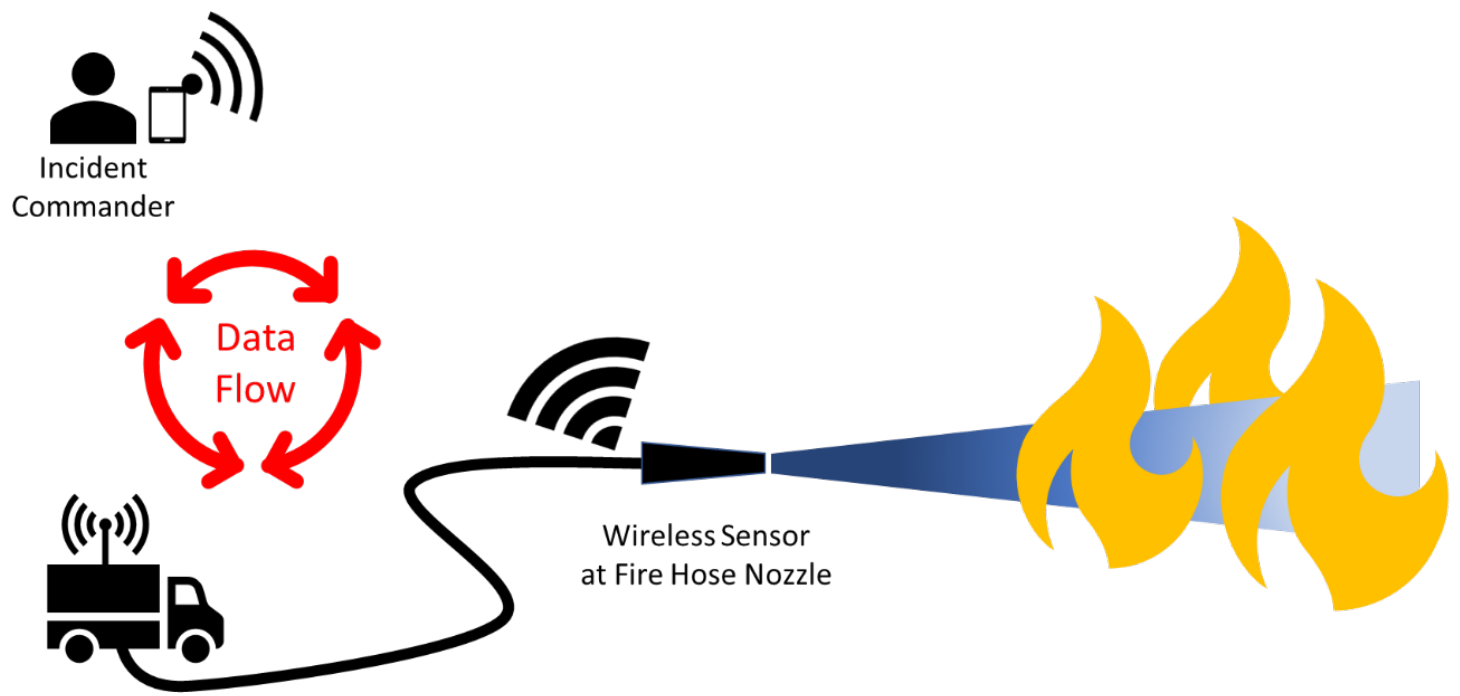

Fire Engine

Fig. 1. A smart sensor network can measure flow rate at the fire hose nozzle and wirelessly transmit the flow rate to the IC and pump operator for decision making. 


\subsection{Current State of the Art}

Consider the following scenario describing a typical house fire with fire fighters using the current fire hose. The first fire engine arrives at the front of a single-family house with smoke showing from behind the house. The first arriving officer conducts his initial size up by walking completely around the house. Concurrently, a fire fighter stretches a $60 \mathrm{~m}$ (200 foot) preconnected $4.5 \mathrm{~cm}$ (1.75 inch) hose from the engine to the front door of the house and brings hand tools from the fire engine. The officer finishes his exterior assessment and the two-person team prepares to enter the house through the front door. When the team is ready to enter the house, they signal to the pump engine operator to charge the hose line with water. The team enters the front door of the house and advances the pressurized hose into the house in search of the fire.

The two-person team inside the house is relying on the water from the hose to protect them from the heat and to extinguish the fire. Once the hose line has been charged, the pump operator may conduct other duties on the fire ground away from the pump panel, including placing ladders to windows of the house, connecting an intake hose from a hydrant to the engine, chocking wheels, etc. Once the suppression team disappears into the house, the pump operator may not know that the fire fighters are flowing water.

Older engines will indicate pressure loss on their pump panel gauge when the hose nozzle is opened. Additional water pressure must then be added to increase the hose pressure after the nozzle is open. This means the pump operator must be at the pump panel to increase the pressure to the target pressure once the nozzle is opened. By increasing pressure to the hose line, the pump operator assumes that water is flowing from the nozzle as intended.

On newer engines the hose pressure can be preset, and once the nozzle is opened and the pressure in the hose line drops, the engine pump will automatically compensate by increasing pressure to achieve the preset target pressure. This means the pump operator does not need to stay at the pump panel to wait for the fire fighters to open the nozzle so the pump operator can increase the pressure. The pump operator may, or may not, be able to hear the pump sounds while standing next to the pump panel as the engine's pump automatically increases water pressure. Unfortunately, this also means the pump operator may not know if water is flowing from the nozzle on the other end of the hose line out of sight inside the house.

Some engines have a flow meter that measures the total flow rate of all the water flowing out of the engine. The flow meter does not measure the flow rate for a specific hose unless only one hose is being used. Since the flow meter is on the engine, it does not necessarily indicate that water is flowing out of a specific hose nozzle as intended.

Currently, communication between the fire fighter at the nozzle and the pump operator or IC is typically done using radios. The fire fighter at the nozzle, or his backup, should be able to communicate by radio to the pump operator or IC to provide feedback about water flow. However, this is not always possible to do with competing radio traffic while the team is advancing the hose and conducting suppression activities that take two hands. Fire fighters in danger may not be capable of operating the hose or radio for help. If their hose nozzle was 
closed prior to their emergency and remains closed, the pump panel will show there is sufficient pressure in the charged hose line yet there is no flow from the nozzle.

Fire engines have a gauge on the pump panel for the amount of water in their supply tank. The water level will decrease when the engine is operating using only its own water supply and water is flowing out of the engine. If the first arriving engine initially supplies water from its own supply tank, the decreasing level of tank water will indicate that water is flowing out of the engine, but not necessarily flowing from the nozzle as intended. If the engine has an external water supply, from a hydrant or tanker, then the volume of water will be replenished, and the tank volume will not indicate that water is leaving the engine. In both of these cases, the engine's water tank level will not clearly indicate if water is flowing from the nozzle.

\subsection{Normal pump pressure, but low nozzle flow due to hose rupture or leak}

Presently, water pressure measured at the fire engine's pump panel is used by the pump operator to determine if water is flowing at the hose nozzle. Fireground threats to normal water flow such as hose damage and hose blockage can make reliable decisions on water pressure misleading. A pressure loss indicated on the fire engine's pump panel may occur when water flows from the nozzle, as intended, or unintentionally through a ruptured hose.

Several fire ground threats could cause a decrease in pressure at the pump panel, falsely indicating a loss in pressure from normal operations while water is not flowing from the nozzle. Hose failures that threaten normal water flow from the hose nozzle include a hose rupture or leak from hose wear and tear, a burn hole in the hose, a leaking coupling, or a hose rupture from being crushed by vehicle tires or structure debris. These threats could cause water to flow unintentionally from somewhere along the hose before the nozzle, decreasing pressure at the pump panel as if water was flowing properly from the nozzle (Fig. 2).

The pressure loss would cause the engine's pump to increase the water pressure, automatically or manually, to account for the decrease in pressure assuming that water is flowing from the nozzle. But if there is a hose failure, less or no water may be flowing from the nozzle where it is needed. The safety of the fire fighters and occupants is threatened by these types of dangerous events; measuring only pressure at the pump panel is deceiving. 


\section{Water Flow Threats - Hose Leak or Rupture}

- Threats to normal water flow:

- Hose hole from normal wear and tear

- Hose burn holes

- Leaking couplings between hose sections

- Hose rupture from a car tire or structural collapse

- Escaping water causes a decrease in water pressure measured at the fire engine pump panel as if water is flowing from the hose nozzle

- Without knowing the hose issue, water pressure in the hose is increased

- Adequate water may or may not flow from the nozzle
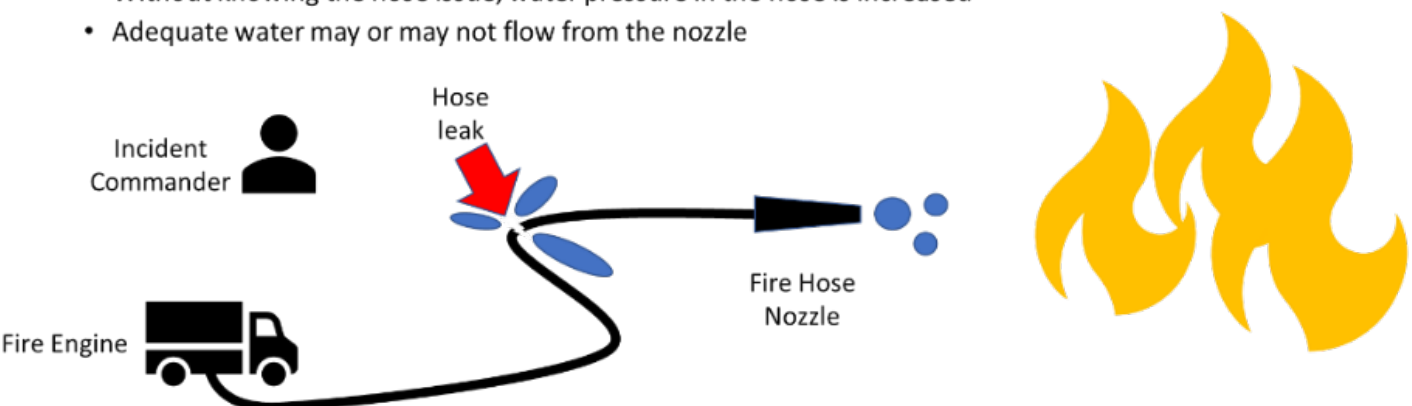

Fig. 2. Threats to normal nozzle flow include holes from wear and tear or burns, leaking couplings, or hose rupture from car tires or structural collapse.

\subsection{Normal pump pressure, but low nozzle flow due to blockage}

When the fire engine measures only water pressure at the fire engine's pump panel, the pump operator will not know if a hose is partially or fully blocked preventing water flow at the nozzle. Sufficient water pressure may show at the pump panel even if the hose is partially or fully blocked preventing water from reaching the nozzle. Several threats on the fireground can partially or fully block a fire hose (Fig. 3). A charged hose line advanced inside a structure could become partially blocked as a result of being crimped around a sharp corner or past a piece of furniture. A hose pinched under a door, under a piece of furniture, under a vehicle tire, or under fallen debris could also reduce water flow at the nozzle. Water flow through the hose could be fully blocked by a closed in-line valve, debris in the hose, or by a closed nozzle bale that cannot be opened by an incapacitated fire fighter. The fully blocked hose would appear at the pump panel to have sufficient pressure. 


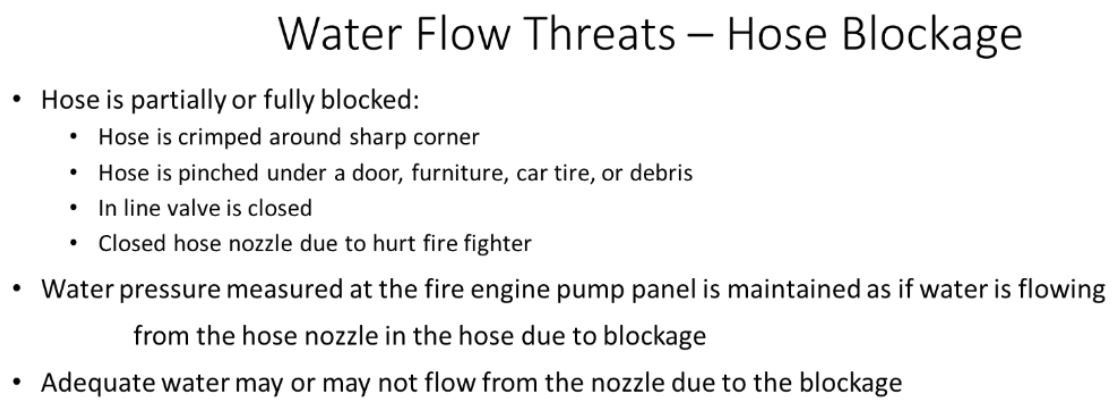

- Water pressure measured at the fire engine pump panel is maintained as if water is flowing from the hose nozzle in the hose due to blockage

- Adequate water may or may not flow from the nozzle due to the blockage

Fig. 3. Normal water flow at the hose nozzle is reduced by a partially blocked hose from crimping or pinching, or a fully blocked hose from a closed valve or closed nozzle bale, yet these dangerous conditions may not be obvious at the pump panel where water pressure may appear normal.

\subsection{Study Goal}

Presently, water pressure measured at the fire engine's pump panel is used by the pump operator to determine if water is flowing at the hose nozzle. Decisions based on water pressure can be misleading because of fireground threats such as hose damage and hose blockage.

The safest way for the IC to know that water is flowing from the hose nozzle is to have realtime water flow information sent to them. A basic graphic display could simplify water flow information and reduce radio traffic when multiple hoses are in operation from several engines at large fires.

The overall goal of this study is to improve fireground situational awareness by developing a wireless sensor network to measure water flow at the fire hose nozzle. Hose vibration data will be collected and then transmitted wirelessly to a device where the data is converted into flow rate in real-time for improved situational awareness and efficient fireground decisions.

The focus of this first technical note is the development of a wired-sensor network to measure water flow in a fire hose. Our approach, which is detailed below, is to collect vibration data, convert it into a flow rate using a well-known algorithm, then display the flow rate at the incident command post. The wired sensors were piezoelectric accelerometers and the dominant frequency and standard deviation of acceleration of the water flow vibrations on the hose were examined as possible metrics to determine flow rate. A second NIST 
technical note report will describe the wireless sensor network and real-time flow measurements [3].

\section{Background Literature}

Different types of sensors have been attached to the outside surface of rigid pipes to measure fluid or gas flow. One type of sensor is an accelerometer. Accelerometers can be attached securely to the outside surface of a rigid pipe and detect the vibration of the fluid flow within the pipe. Different metrics corresponding to the vibrations can then be correlated with the flow rate.

Vibrations from fluid flow can occur in any relatively rigid pipe with fluid, such as water and oil flowing through utility or industrial pipes. Studying pipe vibration is important for utility pipelines because over a long period of time the vibrations can result in fatigue loading and eventually lead to pipe failure. Research has been conducted to measure fluid flow in utility pipelines using accelerometers [4-10]. The study of vibration in flexible pipe like a fire hose has received much less attention.

There are advantages to using external sensors such as accelerometers to measure flow inside a pipe. Accelerometers do not obstruct flow or become contaminated by coming into contact with the fluid inside the pipe. They are easy to install, relocate, maintain, or replace because they are accessible on the outside of a pipe. They are also small and lightweight. In the case of a fire hose, it is important that an external sensor not obstruct water flow and not be heavy or bulky.

Water flowing through a flexible fire hose is turbulent flow and consists of a flow field of eddies. The turbulent kinetic energy of these eddies is transferred from large eddies into smaller eddies whose energy then affects the pressure against the pipe wall. The pressure fluctuations induce pipe vibrations, and accelerometers are sensitive to these types of pipe vibrations.

Two groups of sensors used in the literature for measuring fluid flow in rigid pipes are piezoelectric pressure transducers and piezoelectric accelerometers. Clinch used a cluster of piezoelectric pressure transducers located flush along the inner surface of a water pipe to detect pressure fluctuations from turbulent water flow [11]. A relationship was determined between pressure fluctuations and flow rate. Flow velocities ranged from $5 \mathrm{~m} / \mathrm{s}$ to $13 \mathrm{~m} / \mathrm{s}$ (11 mph to $30 \mathrm{mph}$ ).

A system of three accelerometers was used by Kim and Kim to measure the flow rate on the exterior of a pipe using an external excitor to generate vibrations [12]. Three accelerometers at different distances from the excitor measured the vibration and estimated flow rate based on changing wave number. Sources of error were considered, such as accelerometer spacing, relative accelerometer position, phase mismatch and magnitude mismatch between accelerometers, and measurement noise. Their experimentally determined flow rate was within $12 \%$ of the 'true' flow rate. The internal flow rate was between 0 and $3.08 \mathrm{~L} / \mathrm{s}$ (49 GPM). 
A technique to measure the flow rate from a pipe exterior using accelerometers was developed by Evans et al. [13] and Pittard et al. [14]. A piezoelectric accelerometer attached to the outside surface of a pipe was used to detect turbulent flow-induced pipe vibrations. Data was collected during a 2 second time span at a sampling frequency of $2048 \mathrm{~Hz}$. Fourteen flow rates were used between $400 \mathrm{~L} / \mathrm{min}$ (106 GPM) and $1500 \mathrm{~L} / \mathrm{min}$ (396 GPM). The standard deviation of the time-series signal increased with flow rate.

Evans et al. also looked at peak frequency shifts with flow rate using accelerometers [13]. As the flow rate increased, there was a small decrease in peak frequency. The decrease in peak frequency with increasing flow rate in pipes was also noted by Blevins [15]. An increase in peak amplitude with increasing flow rate was found. Pipe material properties and diameter were shown to affect the vibration and flow rate relationship.

Accelerometers were used by Thompson et al. to determine a relationship between pipe wall vibration and average flow speed, pipe diameter, pipe thickness, and flow passing through baffle plates with various hole sizes [16]. The root mean square of the pipe wall acceleration increased nearly quadratically with the average fluid speed ( $3 \mathrm{~m} / \mathrm{s}$ to $11.5 \mathrm{~m} / \mathrm{s}$ ) and increased with decreasing pipe wall thickness. For the baffle plate experiments, the magnitude of the vibration decreased with increasing downstream distance from the turbulence source.

Dinardo et al. [17] and Campagna et al. [18] used a laser Doppler vibrometer (LDV) to measure pipe vibrations due to internal fluid flow. Dinardo et al. showed a linear relationship between the first harmonic amplitude of the transverse acceleration and the flow rate inside a pipe. Campagna et al. advanced this work and determined that sensitivity of the measurement is influenced by pipe material (steel and PVC) and pipe size. They also showed for a narrow range of increasing flow rates, the peak harmonic frequency decreased.

Medeiros et al. [19] and Medeiros et al. [20] used an accredited flow meter lab to evaluate Evans et al. (2004) flow rate measurement technique using an accelerometer attached to the surface of a water pipe for application to the oil and water industry. The flow rate is estimated from the standard deviation of the accelerometer measurement. Three measurements were taken at each flow rate and the flow rate was also measured by a standard Coriolis flow meter for comparison. Signals caused by the effects of the pump, air compressor, and resonance frequency of the pipeline were discarded by filtering.

The standard deviation of the voltage from both pressure and acceleration sensors had an increasing relationship with flow rate, as shown by Lannes et al. [21] and similarly shown by others for accelerometers $[13,14,16,19,20]$. The flow rate was measured in both straight pipe and pipe bends. The piezoelectric sensors were embedded close to the inner surface of the pipe to increase their sensitivity to the pressure fluctuations from turbulent flow while an accelerometer was attached to the surface of the pipe to detect vibration in the vertical direction for comparison to the pressure sensors. The increase in turbulent flow at the pipe bends increased the sensitivity of the piezoelectric sensors and accelerometers to changes in flow rate [21]. 


\section{Wired Accelerometer Test 1 and Test 2}

\subsection{Introduction - Wired Accelerometer Test 1 and Test 2}

The purpose of Test 1 and Test 2 was to first apply the accelerometer to the exterior of the fire hose, collect data, and to see if a relationship can be determined between the hose vibration sensed by the accelerometer and the flow rate of the water in the fire hose.

\section{2. $\quad$ Methods - Wired Accelerometer Test 1 and Test 2}

Several different types of flow meters were assessed for use in this study such as: turbine, electromagnetic, and pressure differential meters. However, these types of meters were typically too large, heavy, and bulky for use with the fire hose. Alternatively, a smaller, lightweight, exterior, accelerometer was chosen for the fire hose application.

One accelerometer (PCB model 288D01), an integrated electronic piezoelectric (IEPE) transducer, was used to measure both force and acceleration. The mechanical strain of the piezo ceramic material within the accelerometer resulting from vibration is converted to an electrical signal. For this accelerometer, the maximum and minimum acceleration was $\pm 490.5 \mathrm{~m} / \mathrm{s}^{2}$. The maximum and minimum force was $\pm 222.4 \mathrm{~N}$. The frequency range for the accelerometer was up to $5000 \mathrm{~Hz}$. The maximum frequency for data collection was $51.2 \mathrm{kHz}$. Power to the accelerometer was supplied from the data acquisition system. The accelerometer was mounted to a base that was epoxied to the exterior hose fabric (Fig. 4) approximately $31 \mathrm{~cm}$ (12 in) downstream of the water source connection (Fig. 5).

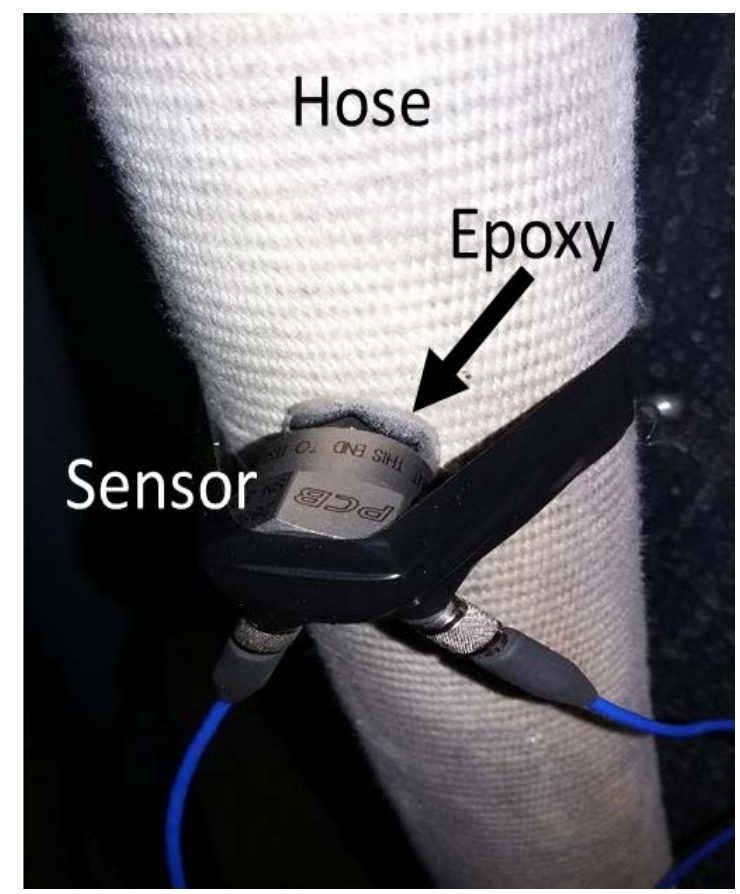

Fig. 4. The transducer base was epoxied to the hose fabric and the accelerometer was screwed tightly to the base. Black electrical tape was applied to provide additional support to the transducer while the epoxy cured. 


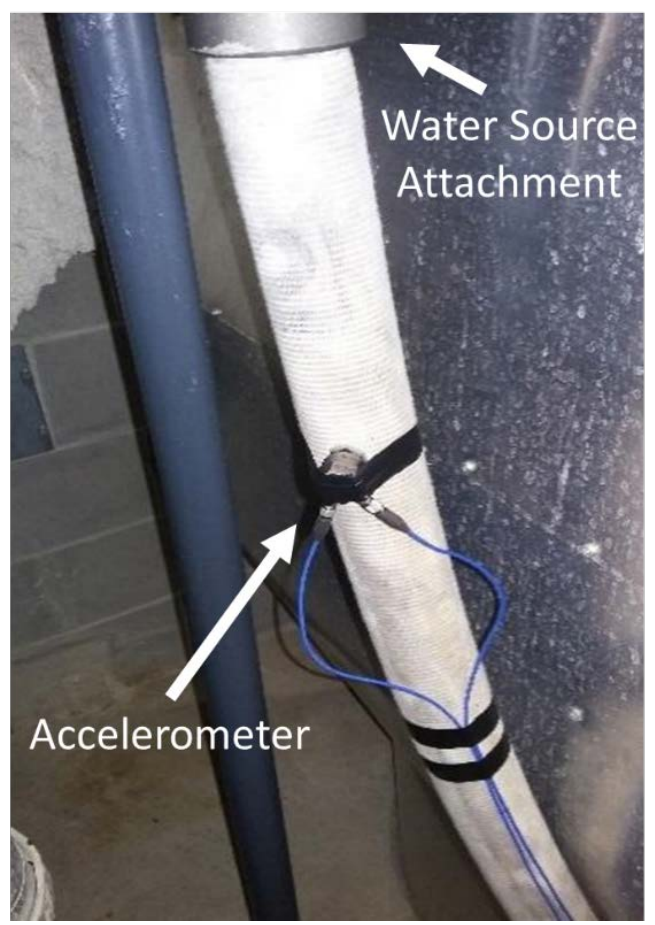

Fig. 5. The transducer was attached to the hose approximately $31 \mathrm{~cm}$ (12 in) downstream from the hose-water source attachment point. Black electrical tape was applied to help provide stress relief to the wire leads from the transducer.

The commercial fire-attack hose used in this study had a nominal $4.5 \mathrm{~cm}$ (1.75 in) inner diameter and was approximately $15 \mathrm{~m}$ (50 ft) long with $3.8 \mathrm{~cm}$ (1.5 in) couplings. It had a polyester inner and outer jacket with EPDM (ethylene propylene diene monomer rubber) synthetic rubber inner lining typical for a commercial fire hose attack line. Water was supplied to the hose from a building interior water supply. The maximum pressure supplied by the water source to the hose was approximately $0.6 \mathrm{MPa}(90 \mathrm{psi})$.

A commercial turbine flow meter was used at the nozzle to measure the reference flow rate during the study. The flow meter was previously shown to provide the correct flow rate following AS/NZS 1221:1997 [22]. For a variety of reasons, the reference flow rate drifted approximately $\pm 3.8 \mathrm{LPM}(1.0 \mathrm{GPM})$ at the highest reference flow rates, but drifted less than approximately $\pm 1.9 \mathrm{LPM}(0.5 \mathrm{GPM})$ at the lower reference flow rates. For consistency, the abbreviation 'LPM' represents $\mathrm{L} / \mathrm{min}$ and 'GPM' represents gallons/min for the remaining text. The turbine flow meter and a dial pressure gauge were attached between the fire hose and the nozzle (Fig. 6). There was sufficiently straight flow upstream and downstream of the commercial flow meter turbine to satisfy the manufacturer's recommendation for maintaining the flow meter accuracy.

The lead wires from the transducer were attached to the channel unit with one channel for force and one for acceleration measured in volts. The channel unit was connected to the data acquisition system (DAS) on a laptop using a USB connection. Data collection software was used to collect and organize the data (Fig. 7). 


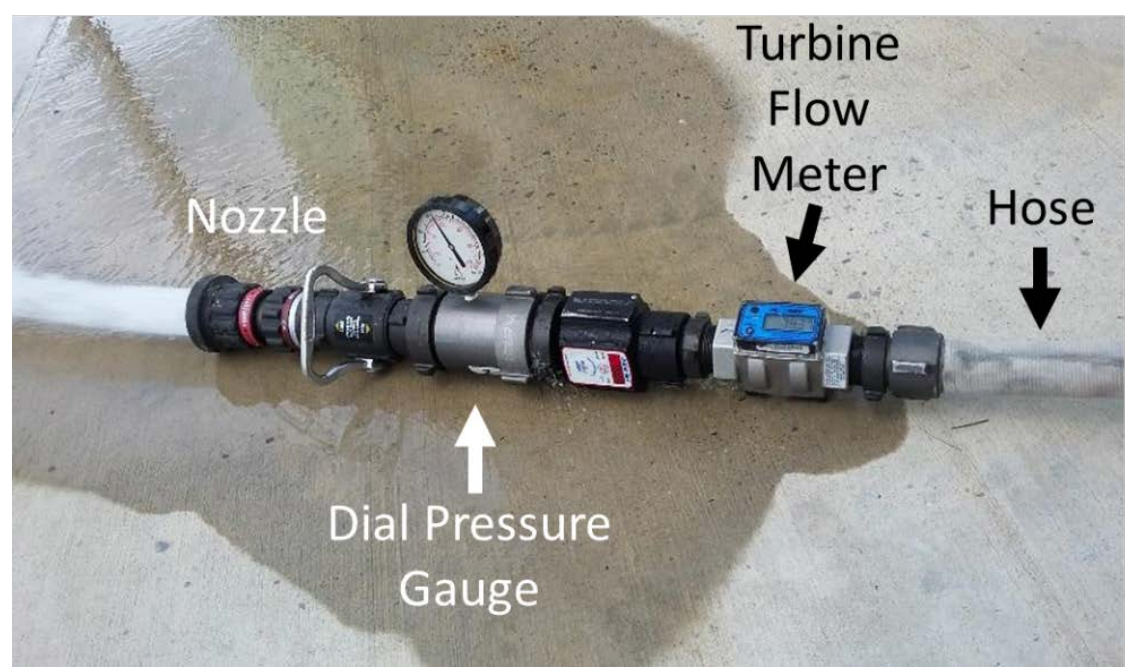

Fig. 6. The in-line turbine flow meter and dial pressure gauge at the nozzle end of the hose during testing.

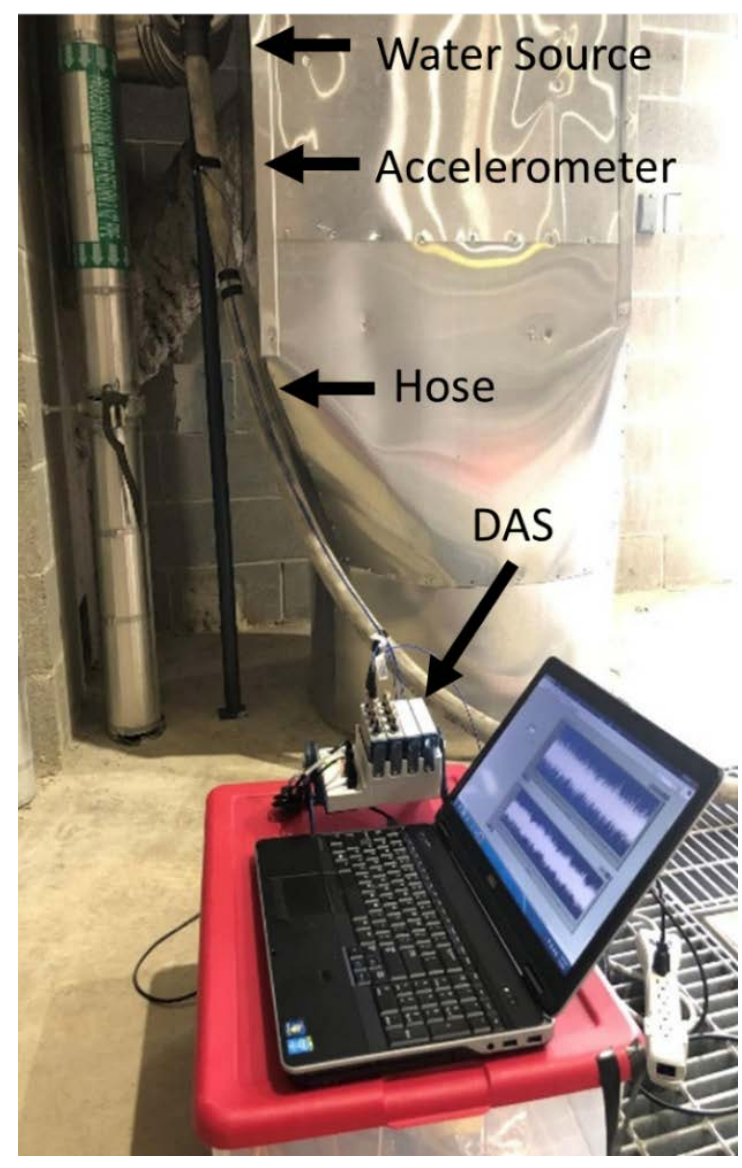

Fig. 7. The wired experiment set up during data collection. The force and acceleration lead wires from the transducer were attached to the DAS and the laptop. 
Baseline acceleration and force data were collected for five, 10-second-long intervals while the hose was pressurized but water was not flowing. Data collected during the five baseline test runs indicated that typical noise vibrations in the hose were in the range of approximately $\pm 0.1 \mathrm{~m} / \mathrm{s}^{2}$.

Impact testing during Test 1 was done with the hose fully pressurized but without flow (0 LPM) before the flow testing started. Five impacts were made during a 10-second-long interval using an impact hammer on the force sensor of the transducer (Fig. 8). Ten, 10second-long, data files were collected at the maximum frequency of $51.2 \mathrm{kHz}$. The impact testing resulted in accelerations between $-400 \mathrm{~m} / \mathrm{s}^{2}$ to $150 \mathrm{~m} / \mathrm{s}^{2}$ and a force measurement less than $30 \mathrm{~N}$.

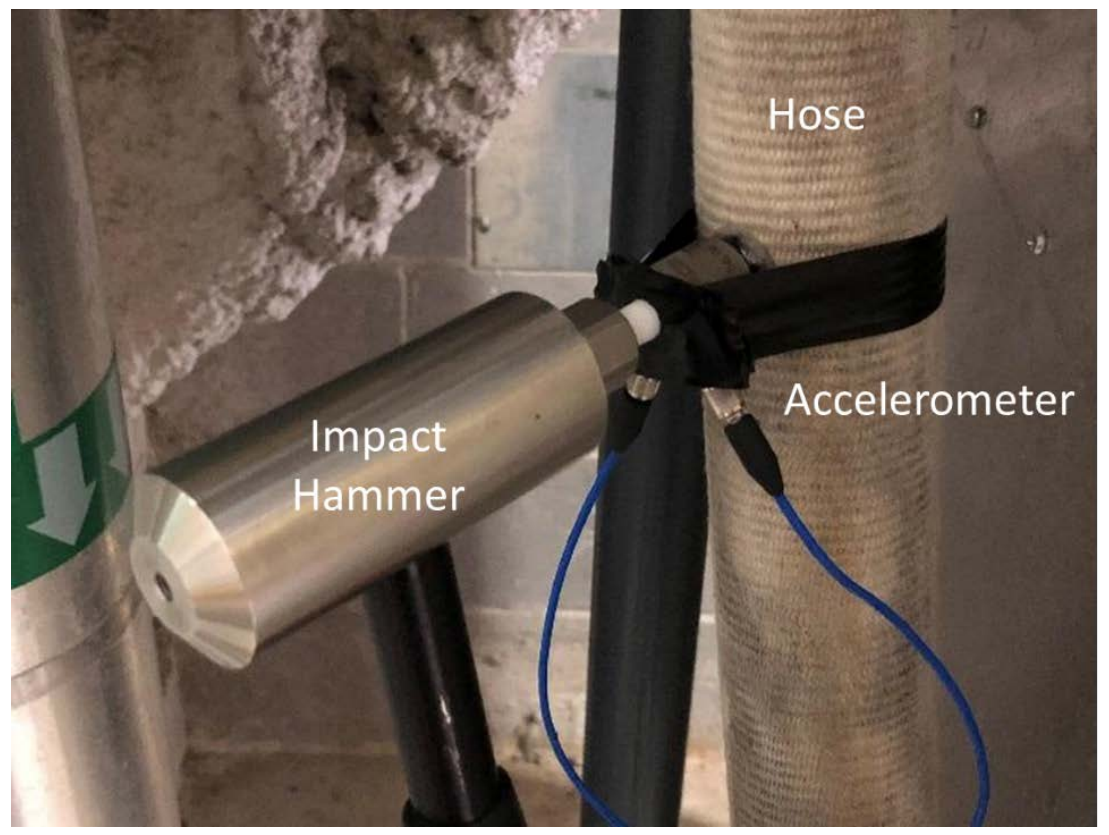

Fig. 8. The impact hammer was used on the force sensor of the transducer.

After the fire hose was pressurized with water, the nozzle bale was opened and the flow rate measured using the turbine flow meter at the nozzle (Fig. 9). The flow rates during Test 1 were approximately 38 LPM (10 GPM) apart, beginning with 0 LPM and ending at the highest flow rate that was achieved with the water source that day, 469 LPM (124 GPM), for a total of 13 flow rates. At each flow rate, 5 consecutive, 10 -second-long test intervals of data were collected. A sampling rate of $51.2 \mathrm{kHz}$ was used. Pressure was measured by a dial pressure gauge at the nozzle and noted for each flow rate.

During Test 2, a maximum flow rate of 538 LPM (142 GPM) was achieved and used to start the series of flow tests and the flow rate was decreased approximately 19 LPM (5 GPM) to 0 LPM, for a total of 30 flow rates. At each flow rate, 50 consecutive, 3-second-long test intervals of data were collected. A data sampling rate of $5 \mathrm{kHz}$ was used. Although the 
duration of the test intervals and the sampling frequency was reduced to improve data management, it was determined that sufficient data was still being captured.

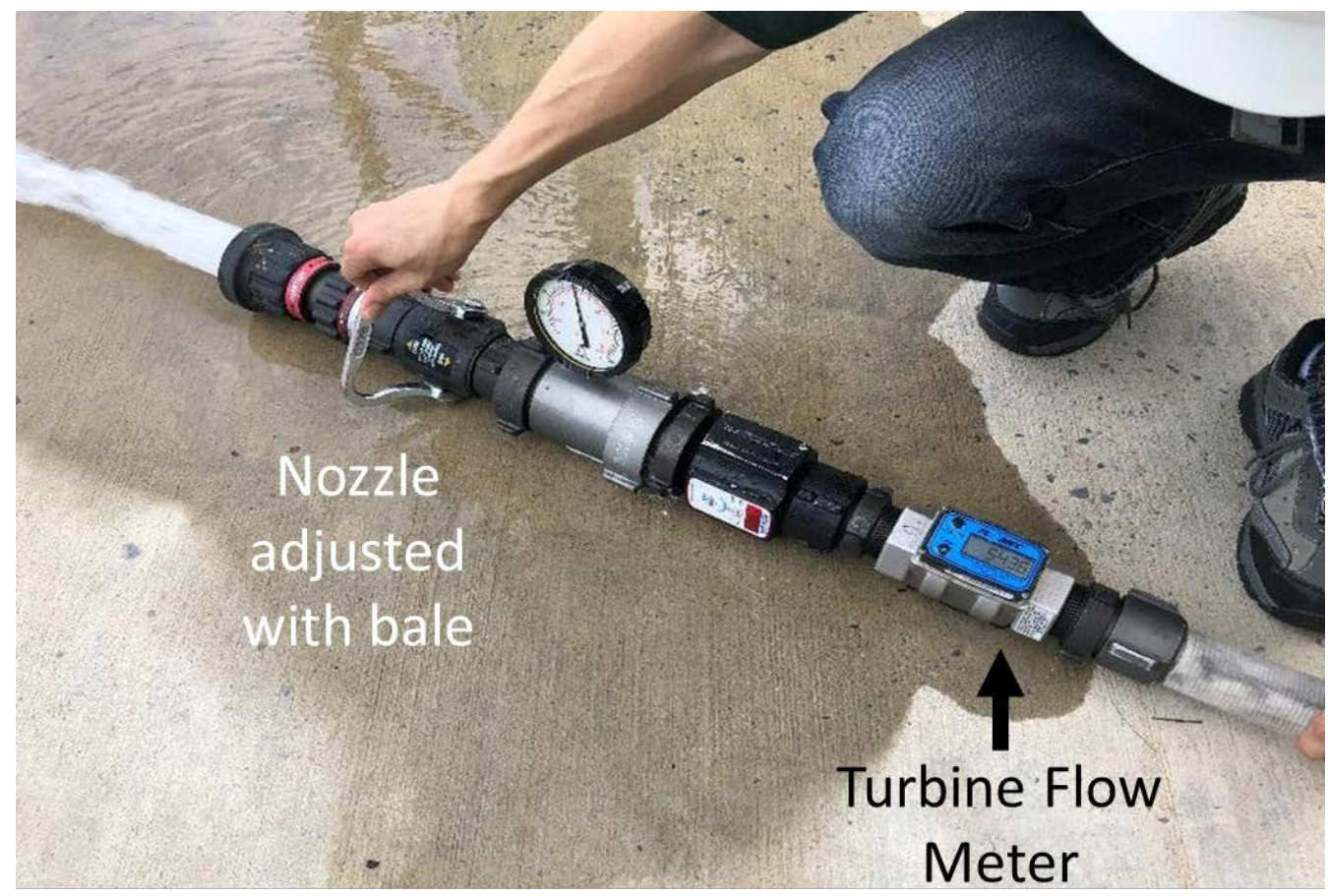

Fig. 9. The flow rate was adjusted for each setting using the nozzle while reading the in-line turbine flow meter.

During Test 2, impact testing was done at the following flow rates: 0 LPM, 189 LPM (50 GPM), 379 LPM (100 GPM), and 568 LPM (150 GPM). At each flow rate, 30 consecutive, 3-second-long files were collected, each file with one impact. Data was collected at a sampling frequency of $5 \mathrm{kHz}$. A different impact hammer was used to excite the sensor at lower frequencies, below $100 \mathrm{~Hz}$, as compared to the previous test.

\section{3. $\quad$ Results and Discussion - Wired Accelerometer Test 1 and Test 2}

The first step of this study was to apply a wired sensor and then to determine a metric to measure flow rate. The metric must provide a consistent relationship to flow rate that would also eventually allow for determining the flow rate in the hose in real-time.

The first metric chosen was the standard deviation of the acceleration, similar to the metric also chosen by other researchers for measuring fluid flow in rigid pipe [13, 14, 16, 19-21]. In general, previous researchers determined that the standard deviation of acceleration tends to increase with increasing flow rate in rigid pipes.

A sample time-series plot for 0.3 seconds of raw accelerometer data is shown (Fig. 10) for a single flow rate. The standard deviation for all the data points is calculated to represent the spread of the acceleration signal. Based on previous research it was expected that as the flow rate increased, the amplitude of this signal would also increase for the flexible hose. 


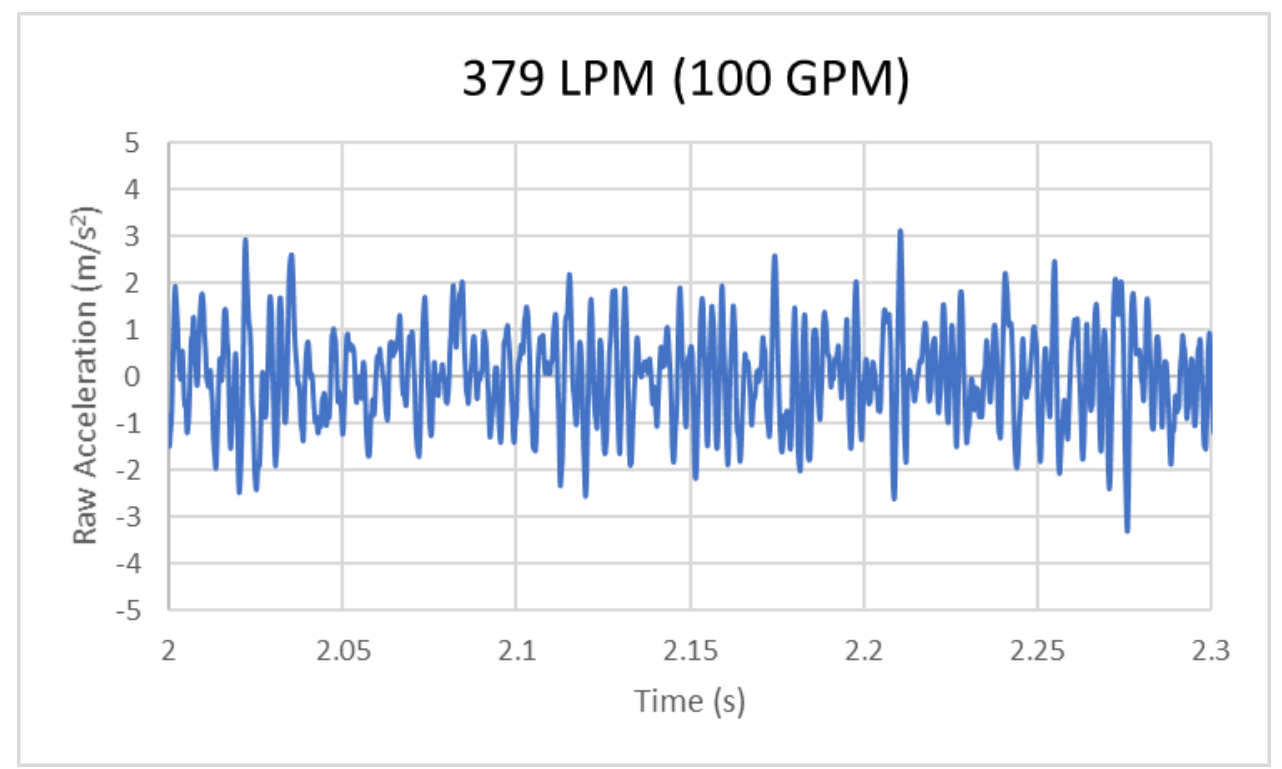

Fig. 10. A sample of raw acceleration data from an accelerometer during a flow test (379 LPM (100 GPM)) for a 0.3-second-long time period. The standard deviation of the acceleration signal is used as a metric.

Another metric chosen was the dominant frequency at each flow rate. The time-series data was converted to the frequency-domain using a Fast Fourier Transform (FFT). A dominant frequency at each flow rate was determined based on the peak frequency from the power spectrum (Fig. 11). Similar decreasing power spectral density curves with increasing frequency, as seen in Fig. 11, have been reported [21]. Based on previous research, the natural frequency of a rigid pipe system generally decreases with increasing water flow rate through the pipe $[13,15,18]$.

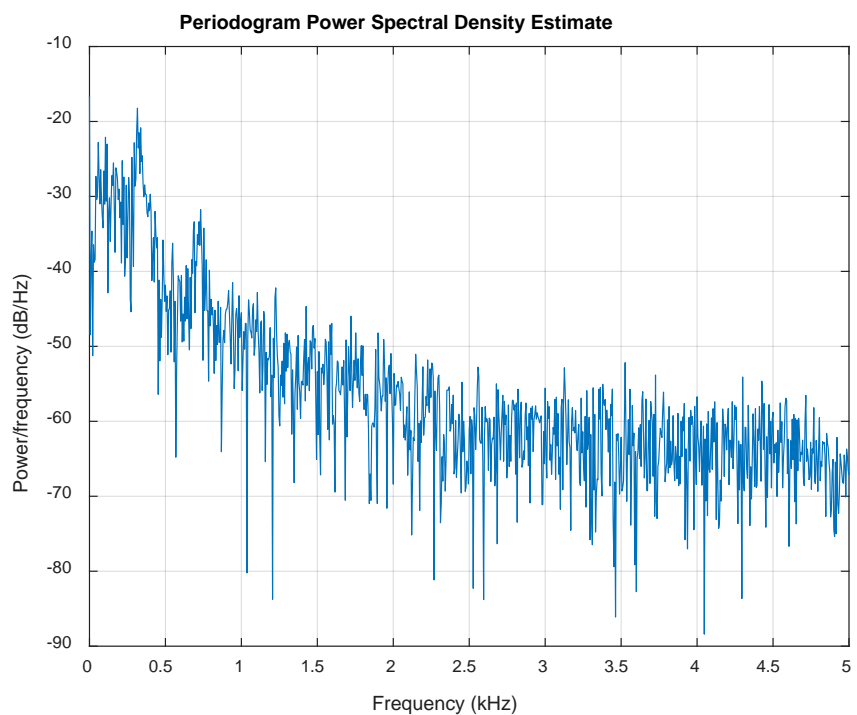

Fig. 11. A sample of the dominant frequency based on the power spectrum. A peak can be seen around $300 \mathrm{~Hz}$. 


\subsubsection{Results and Discussion - Wired Accelerometer Test 1}

The standard deviation of acceleration was determined for each flow rate (Fig. 12). Although at each flow rate, 5 consecutive, 10 -second-long intervals of data were collected at a sampling rate of $51.2 \mathrm{kHz}$, the data for each interval were very similar. Hence, only one 10second-long test interval was used to determine the standard deviation of acceleration. At a sampling rate of $51.2 \mathrm{kHz}$, the single 10 second interval contained a total of $512 \mathrm{k}$ data points. Since this was the first test, a high sampling rate was used to capture a full data set.

The trend in Fig. 12 shows that the standard deviation of acceleration increased fairly linearly as the flow rate increased until 344 LPM (91 GPM). After the peak, the standard deviation of acceleration began decreasing even as the flow rate continued to increase.

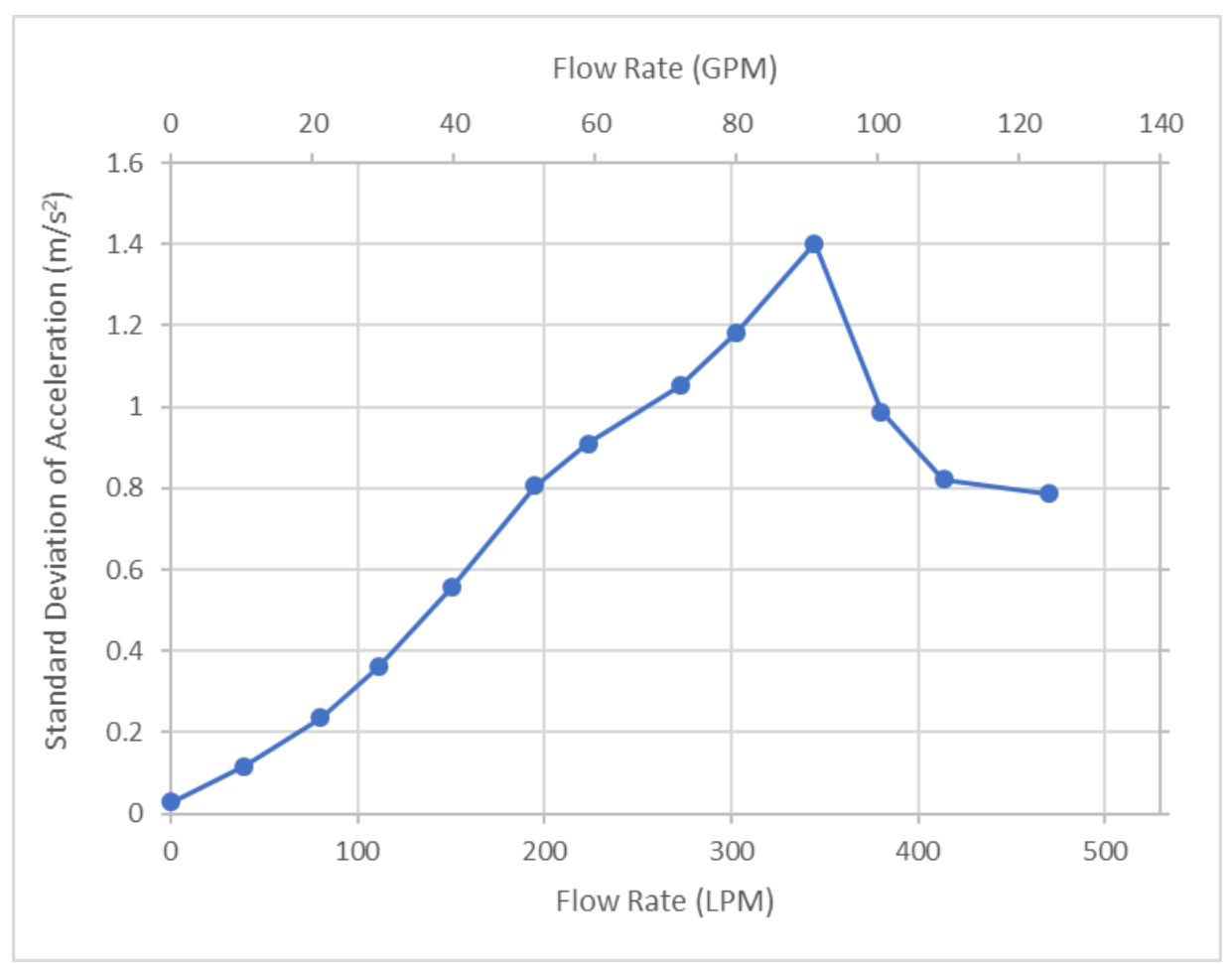

Fig. 12. Standard deviation of acceleration versus flow rate for Test 1. A peak is noted around 344 LPM (91 GPM).

The impact testing on the force sensor on the accelerometer showed a dominating frequency around $450 \mathrm{~Hz}$. Initially, a high pass filter was applied to the analysis so that data collected with a frequency of less than $500 \mathrm{~Hz}$ was ignored to avoid the impact of the dominant frequency. With the filtering, an almost linear relationship was observed between the standard deviation of acceleration and flow rate for the entire flow range. However, this linear trend especially throughout the upper range of flow rates did not occur for any of the subsequent tests (Test 2 and Test 3). Filters in the data analysis were removed. The dominant frequency at each flow rate was also determined for Test 1, yet the relationship was not consistent with flow rate. The inconsistency may have been due to the location of the 
accelerometer on the hose close to the water source, or the hose hanging vertically down from the connection with the water source.

\subsubsection{Results and Discussion - Wired Accelerometer Test 2}

Thirty flow rates were chosen from 0 LPM to 538 LPM (142.2 GPM), set in 19 LPM (5 GPM) increments for Test 2. Acceleration data from the single accelerometer located in the same position as in Test 1 was collected 50 consecutive times, for 3 seconds each, in separate data files at each flow rate at a sampling rate of $5 \mathrm{kHz}$. Data among the 50 consecutive runs was similar and therefore only one, 3-second-long, test interval was used. At a sampling rate of $5 \mathrm{kHz}$, the single 3-second-long interval contained a total of 15k data points. A lower sampling rate was used for Test 2 than for Test 1 but was sufficient in capturing a full set of data with frequencies below the Nyquist value of $2.5 \mathrm{kHz}$. Software processed the raw data to determine the standard deviation of the acceleration.

Standard deviation of acceleration was plotted versus flow rate (Fig. 13). The trend of the data was similar to Test 1 in Fig. 12. In Test 2 the standard deviation peaked, around 397 LPM (105 GPM) after a fairly linear region, and then decreased. The dominant frequency at each flow rate was also determined, however, similar to Test 1 , the relationship was not consistent with flow rate which may have been related to the accelerometer being in the same position on the vertical hanging hose section.

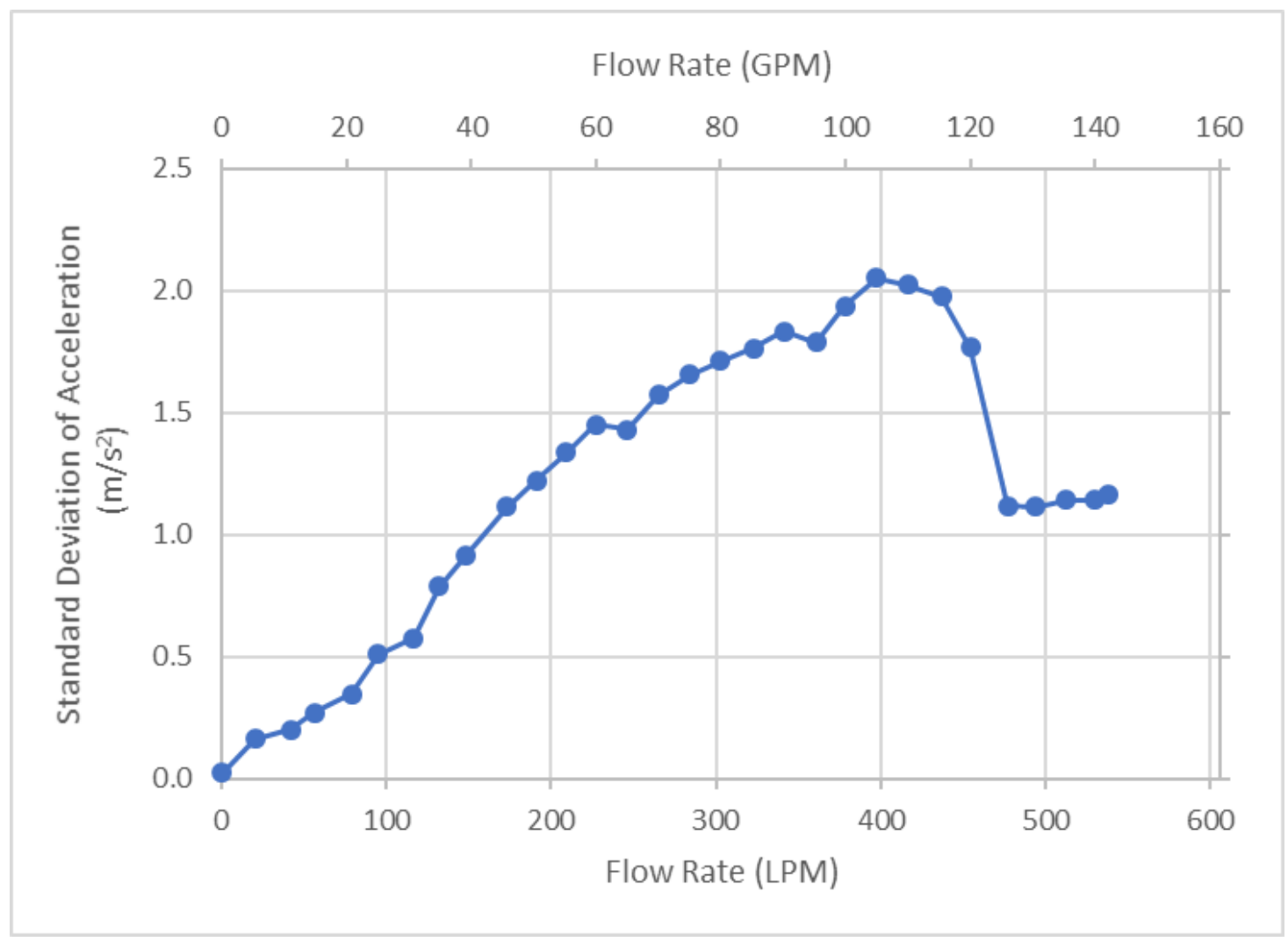

Fig. 13. Standard deviation of acceleration versus flow rate for Test 2. 


\section{Wired Accelerometers Test 3 - Four Accelerometer Study}

\subsection{Introduction - Wired Accelerometers Test 3}

Based on the previous experiments with the single accelerometer, Test 3 was designed to include four accelerometers to collect data. One accelerometer was located at each end of the hose, and two accelerometers were in the middle. Since the overall goal of this project is to measure water flow at the nozzle end of the hose, one of the accelerometers was placed close to the nozzle.

\section{2. $\quad$ Methods - Wired Accelerometers Test 3}

The experimental set up for this study included four piezoelectric accelerometers. The piezoelectric accelerometers at either end of the hose (PCB model 288D01) measured acceleration $\left(10.2 \mathrm{mV} /\left(\mathrm{m} / \mathrm{s}^{2}\right)\right.$ and stand about $2 \mathrm{~cm}$ high. They were mounted on bases epoxied to the outer surface of the hose (Fig. 14). The downstream accelerometer (labeled 'Front') was located approximately $3 \mathrm{~m}$ (10 ft) from the nozzle and the hose rested in grass (Fig. 15). The upstream accelerometer (labeled 'Back') was located approximately $2.4 \mathrm{~m}$ $(8 \mathrm{ft})$ from the hose attachment to the water source and the hose was positioned flat on the concrete floor. Both accelerometers communicated over the wired network to the data acquisition system.

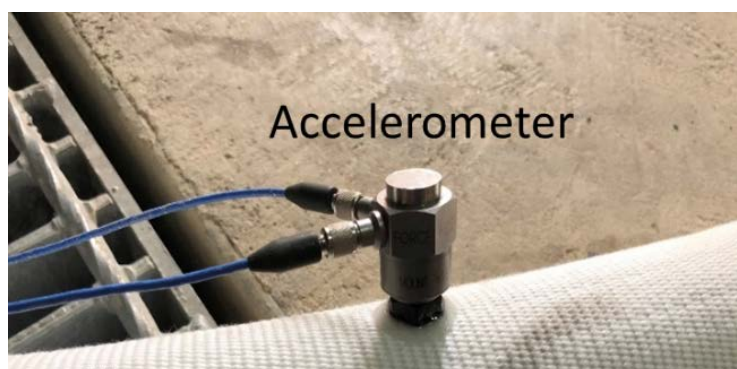

Hose

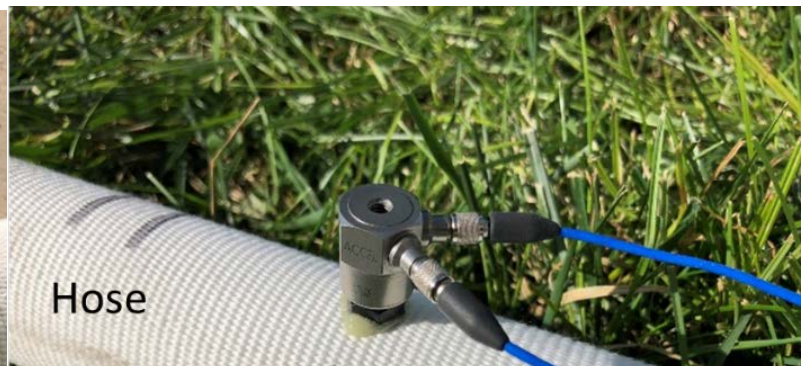

Accelerometer

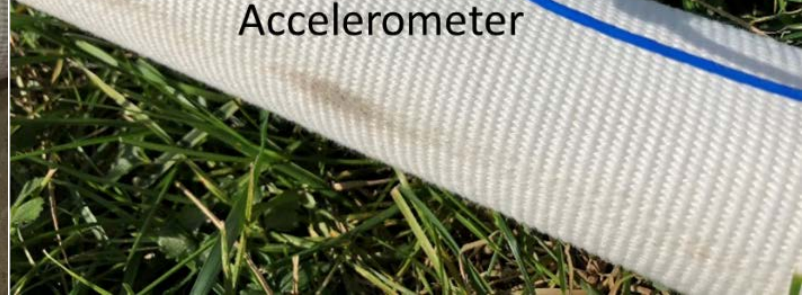

Fig. 14. The two accelerometers at the upstream (Back) location (on the concrete floor (left), and the downstream (Front) location outside in the grass close to the nozzle (right). 


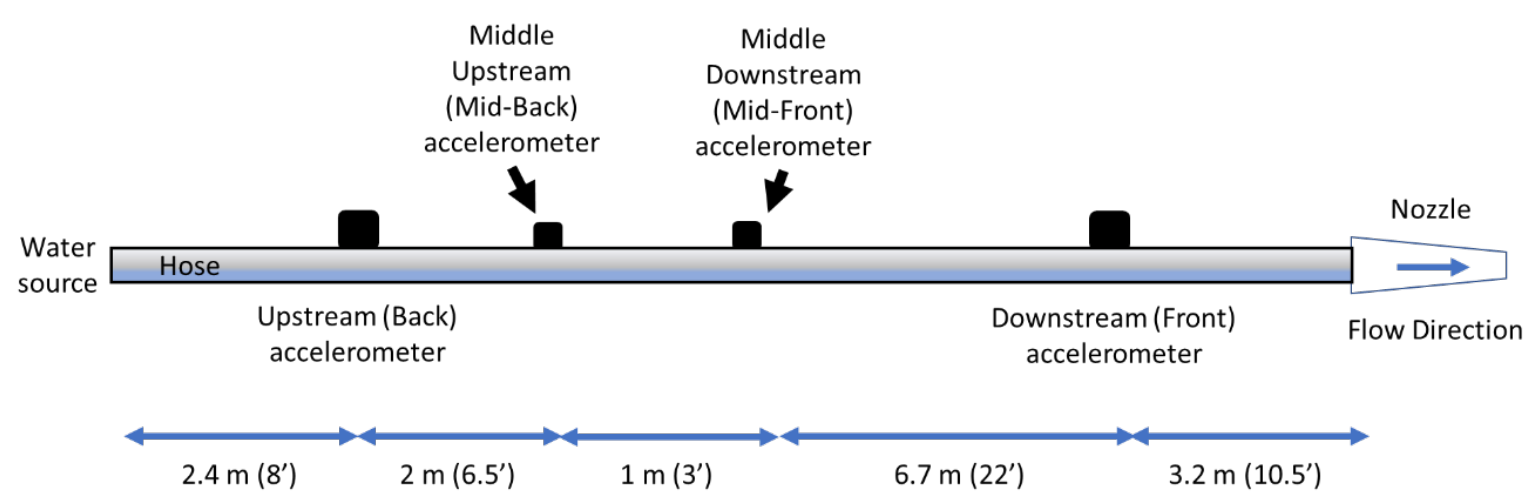

Fig. 15. The four accelerometer locations along the $15 \mathrm{~m}(50 \mathrm{ft})$ fire hose.

The two middle accelerometers (PCB model 352C33) measured acceleration $\left(10.2 \mathrm{mV} /\left(\mathrm{m} / \mathrm{s}^{2}\right)\right)$ and were also about $2 \mathrm{~cm}$ high. The two middle accelerometers (labeled 'Mid-Front' and 'Mid-Back') were located on a section of hose that was flat on the concrete floor (Fig. 16). The voltages from the accelerometers were collected by software. The accelerometers were wired to the data acquisition system and power was supplied from the data acquisition system.

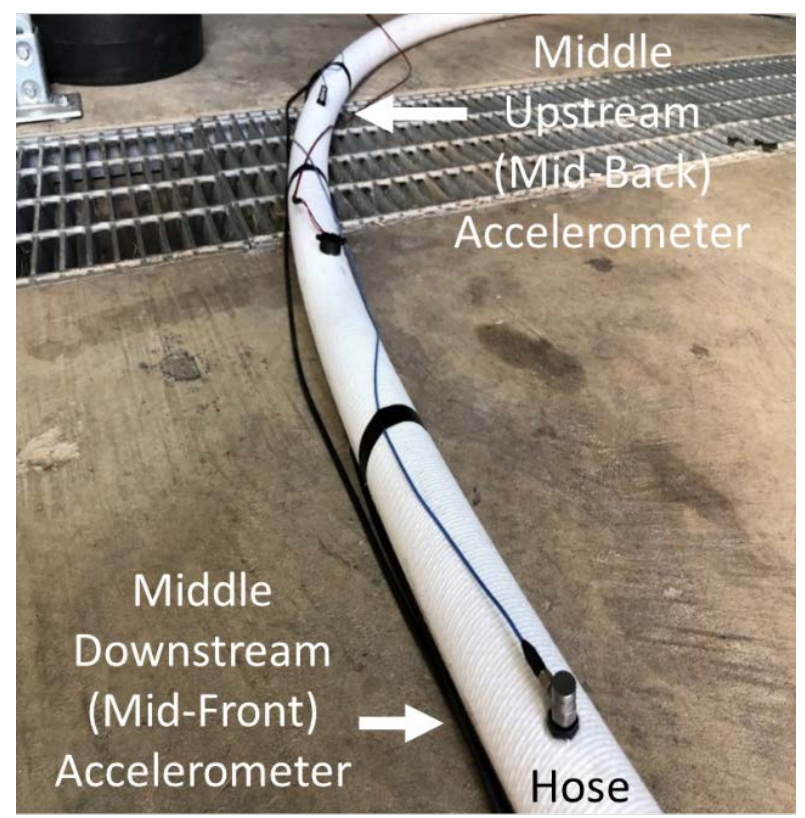

Fig. 16. The two accelerometers approximately $1 \mathrm{~m}(3 \mathrm{ft})$ apart were attached to the hose resting on the concrete floor.

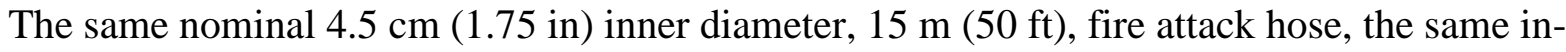
line turbine style commercial flow meter, in the same configuration from Test 1 and Test 2 was used for Test 3 (Fig. 17). The highest flow rate consistently achieved during Test 3 was approximately 606 LPM (160 GPM). The flow rate was then lowered in 19 LPM (5 GPM) increments until 0 LPM. 
The lead wires from the accelerometer were attached to the DAS connected to a laptop via a USB port. The same data collection software from Test 1 and Test 2 was used to collect and organize the data for Test 3 (Fig. 18).

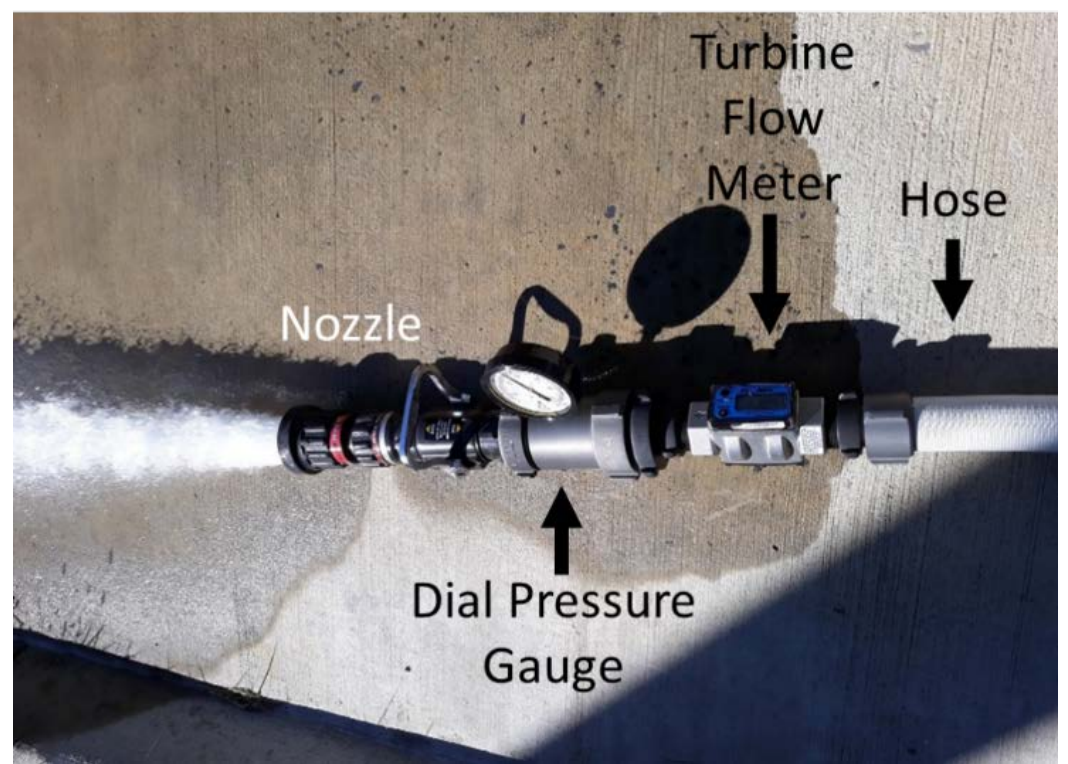

Fig. 17. Nozzle, dial pressure gauge, and turbine flow meter at the downstream (Front) end of the fire hose.
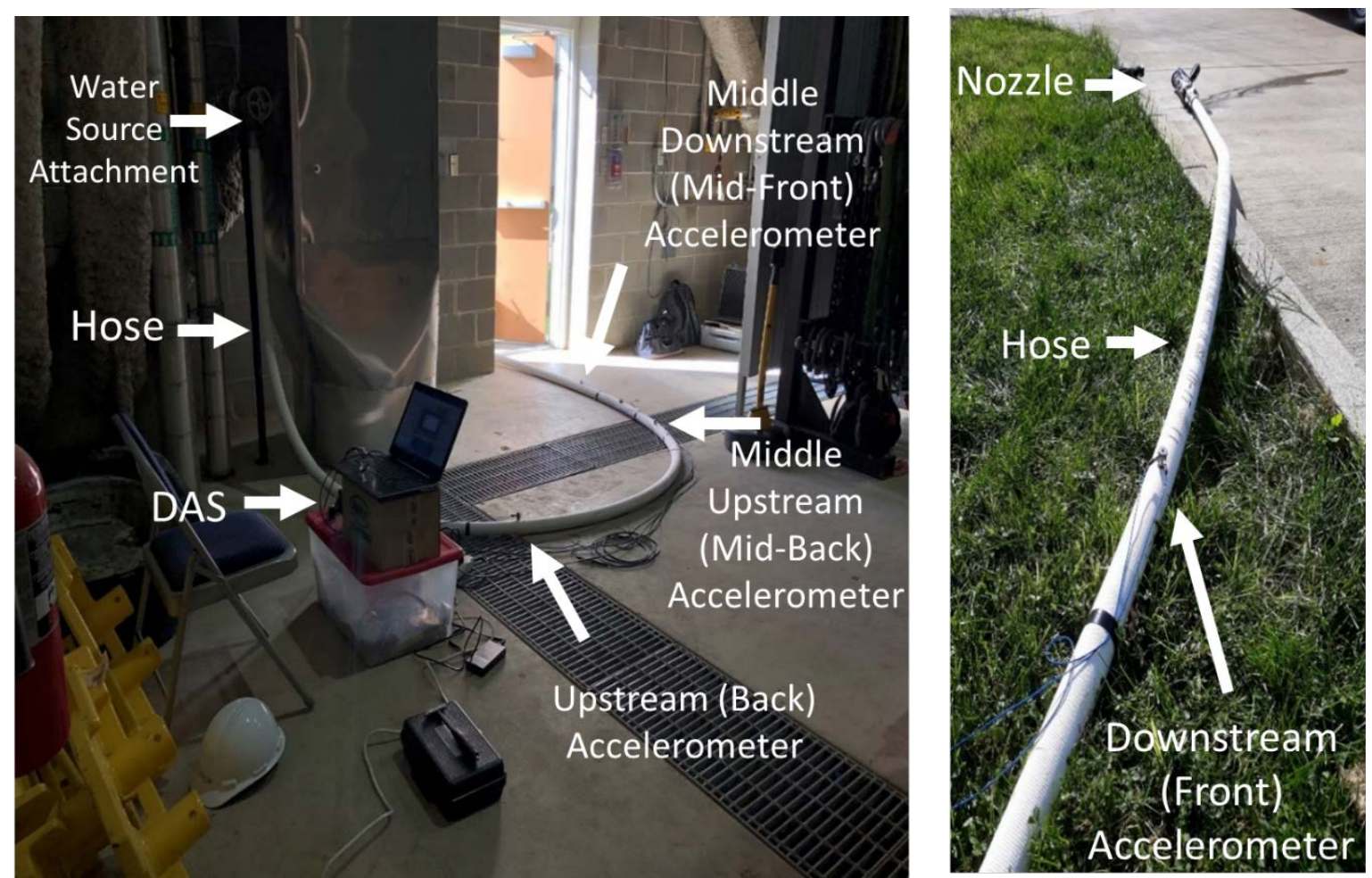

Fig. 18. The fire hose attached to the building water source and three accelerometers on the floor (left), and the downstream (Front) accelerometer in the grass and the nozzle (right). 
The hose was pressurized with the nozzle closed and the dial gauge measured approximately 0.6 MPa (90 psi). Initial baseline data was collected with no flow to confirm all four accelerometers were working correctly and to determine the baseline noise vibrations. The baseline data collected indicated that the non-flow, noise, vibrations were in the range of approximately $\pm 0.1 \mathrm{~m} / \mathrm{s}^{2}$.

The nozzle was opened, and the target flow rate was set using the nozzle bale to regulate the water flow. The reference flow rate was measured by the turbine flow meter at the nozzle. The data collection program was started and vibration data from all four accelerometers was collected for 50 consecutive 3-second-long increments at a sampling frequency of $5 \mathrm{kHz}$.

Impact testing was done using a rubber-tipped impact hammer (Fig. 19) on both upstream (Back) and downstream (Front) accelerometers during the following approximate flow rates to determine dominant frequencies: 606 LPM (160 GPM), 454 LPM (120 GPM), 303 LPM (80 GPM), 151 LPM (40 GPM), and 0 LPM. The impact profiles of thirty impacts were collected. The impact testing resulted in accelerations between approximately $-400 \mathrm{~m} / \mathrm{s}^{2}$ to $150 \mathrm{~m} / \mathrm{s}^{2}$ (and a force less than $30 \mathrm{~N}$ ).

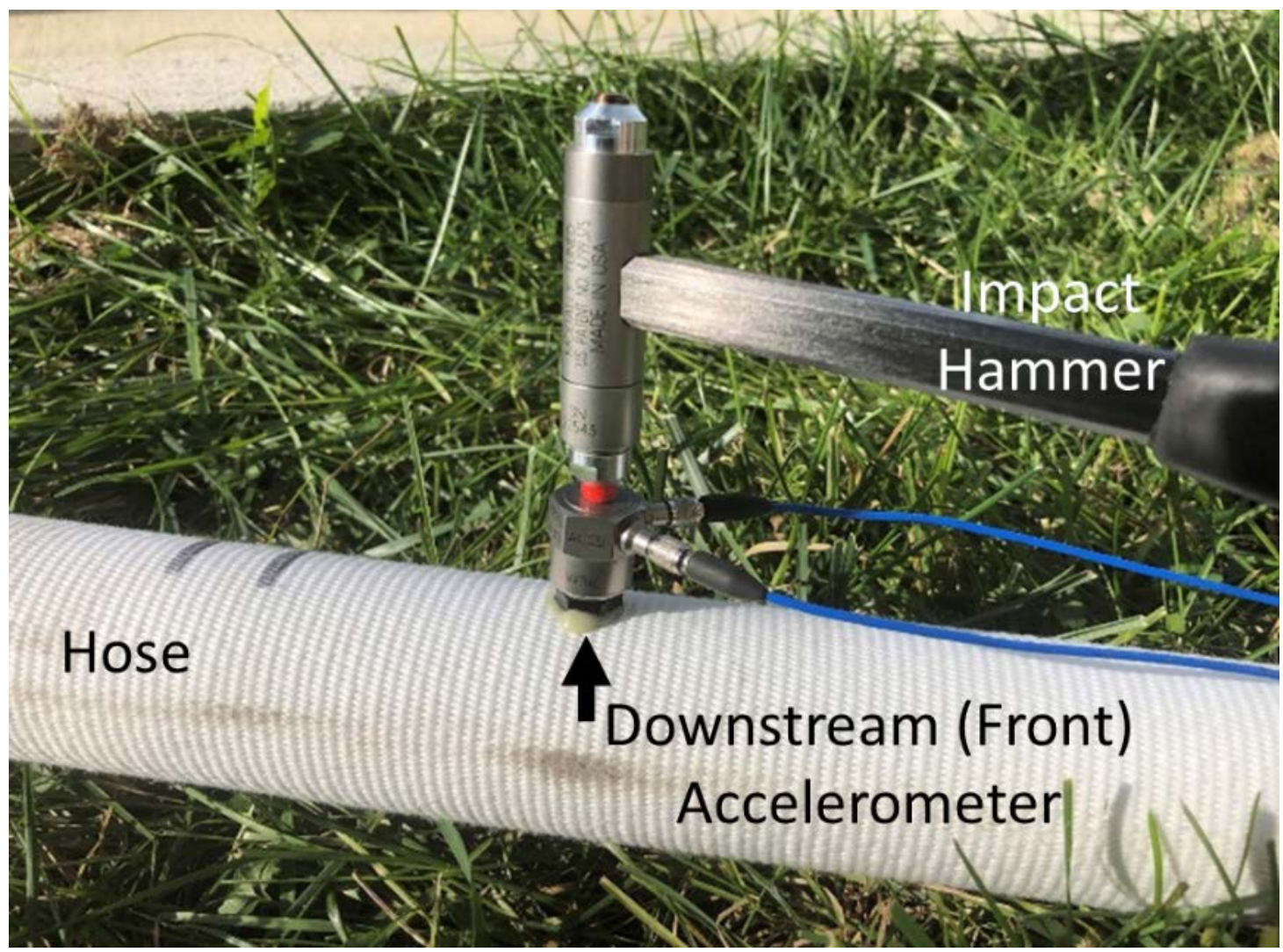

Fig. 19. Impact testing on the downstream (Front) accelerometer using the rubber-tipped impact hammer. 


\section{3. $\quad$ Results and Discussion - Wired Accelerometers Test 3}

\subsubsection{Results and Discussion - Wired Accelerometers Test 3 - Standard Deviation of Acceleration}

The standard deviation of acceleration was calculated from the raw acceleration data and plotted versus flow rate at each of the four accelerometer locations along the hose (Fig. 20 23). The trend at all four accelerometer locations was similar to that of Test 1 and Test 2 , where the standard deviation of acceleration generally increased until peaking and then decreased. Data among the 50 consecutive runs was similar and therefore only one 3-secondlong test interval was used.

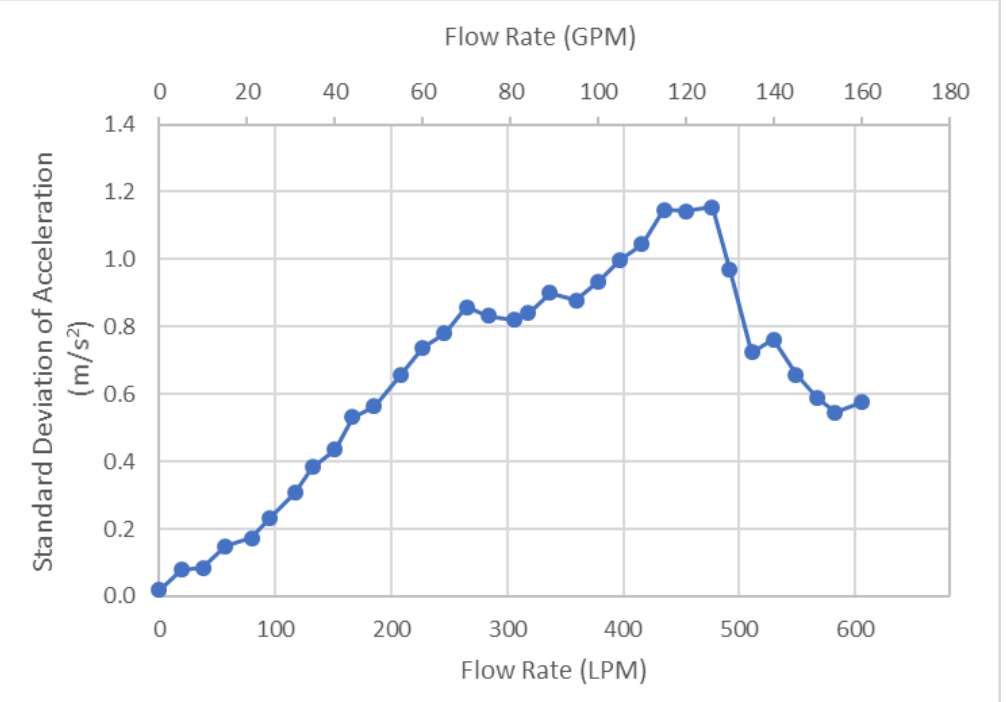

Fig. 20. The standard deviation of acceleration versus flow rate for the accelerometer in the upstream (Back) location.

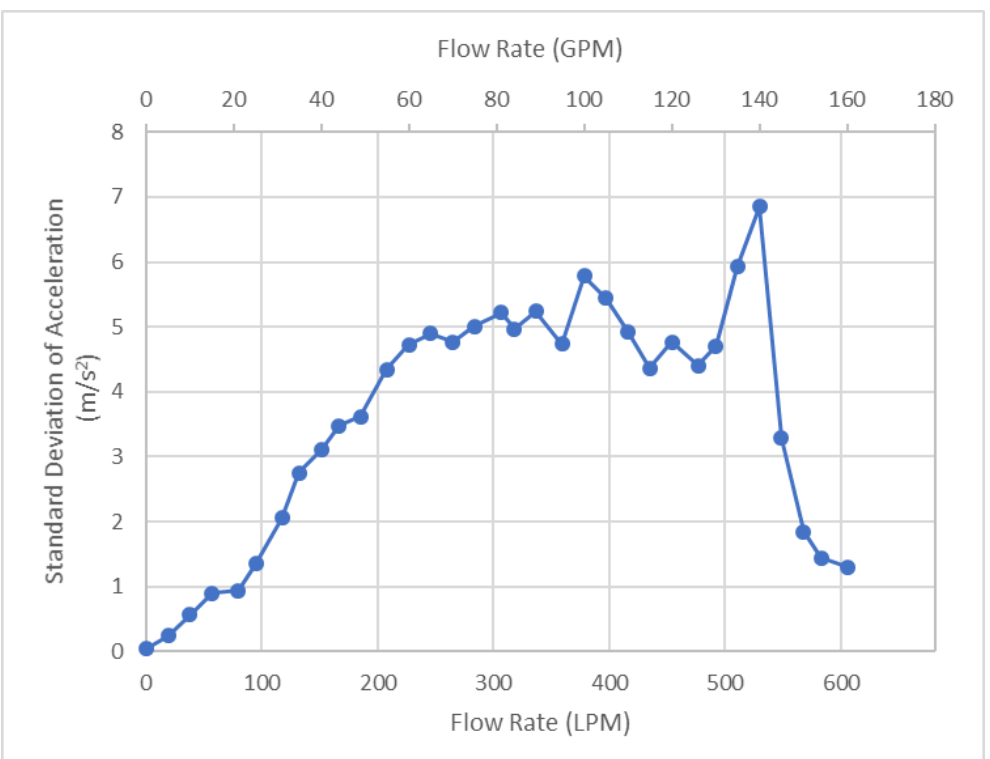

Fig. 21. The standard deviation of acceleration versus flow rate for the accelerometer in the downstream (Front) location, closest to the nozzle. 


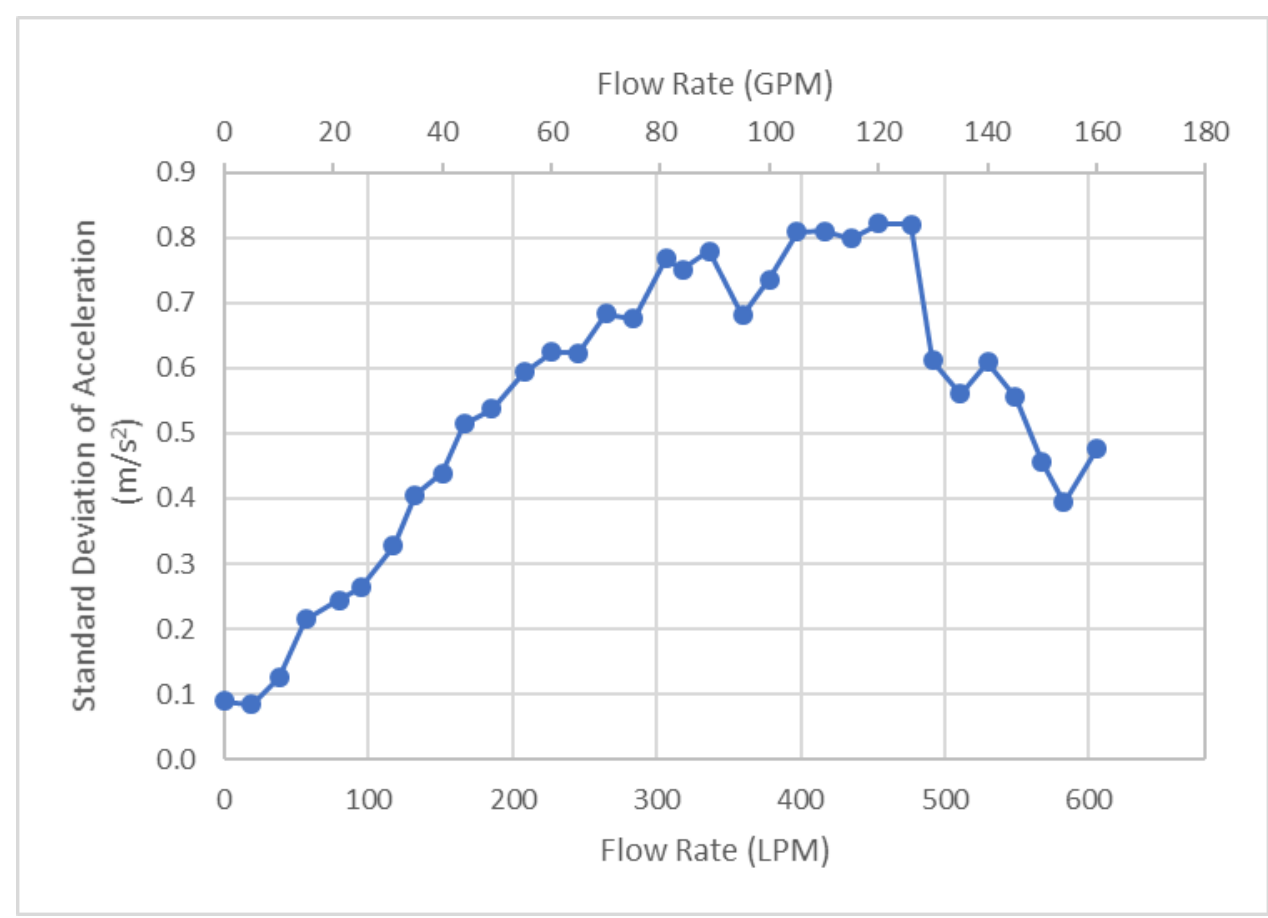

Fig. 22. The standard deviation of acceleration versus flow rate for the accelerometer in the middle upstream (Mid-Back) location.

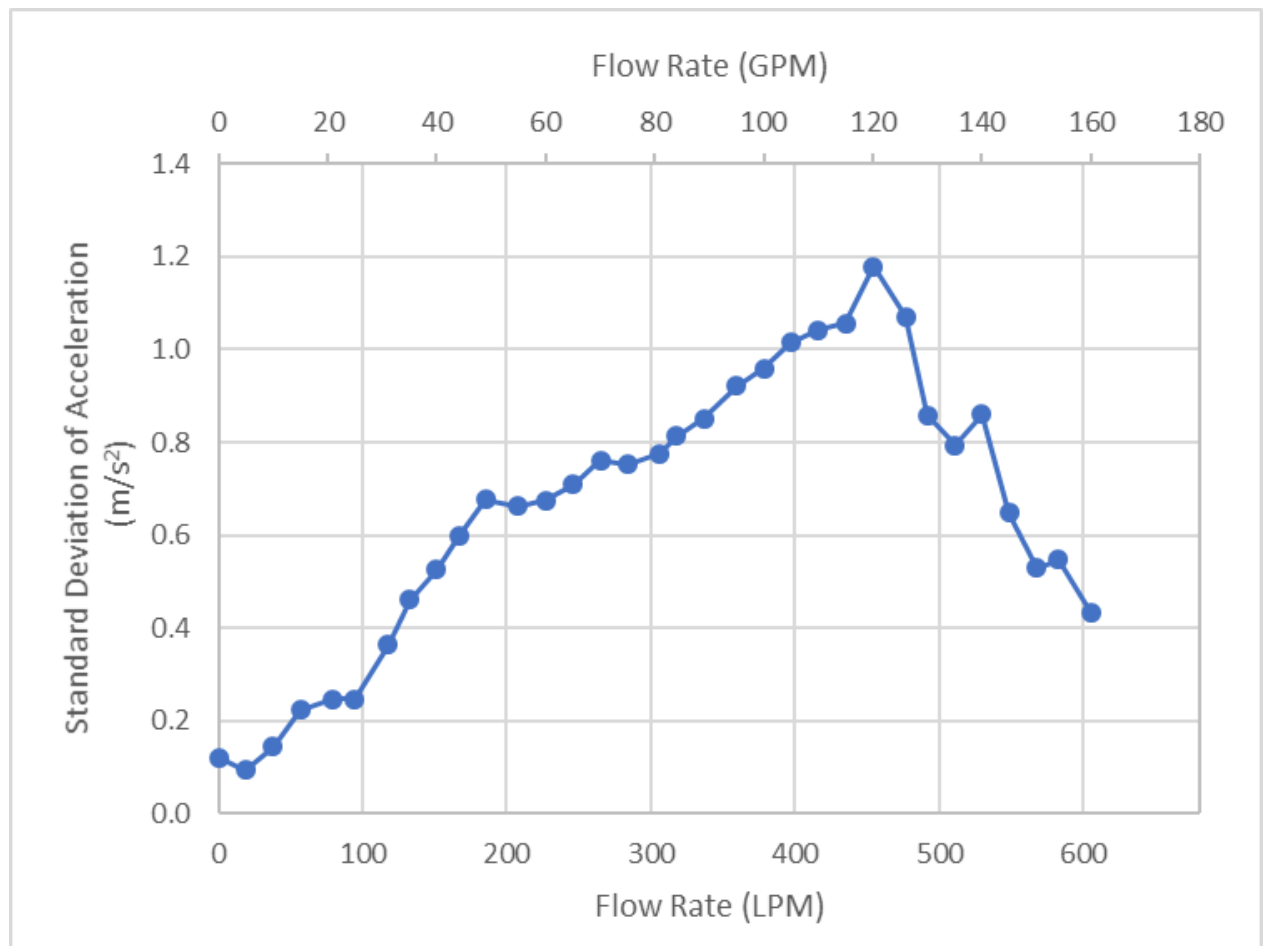

Fig. 23. The standard deviation of acceleration versus flow rate for the accelerometer in the middle downstream (Mid-Front) location. 
When the standard deviation values for all four accelerometer locations were plotted together (Fig. 24), the standard deviation values at the front downstream location were clearly larger than the values from the other three locations. Nonetheless, all trends for the four locations had a similar increasing relationship for lower flow rates and then peak before following a decreasing trend.

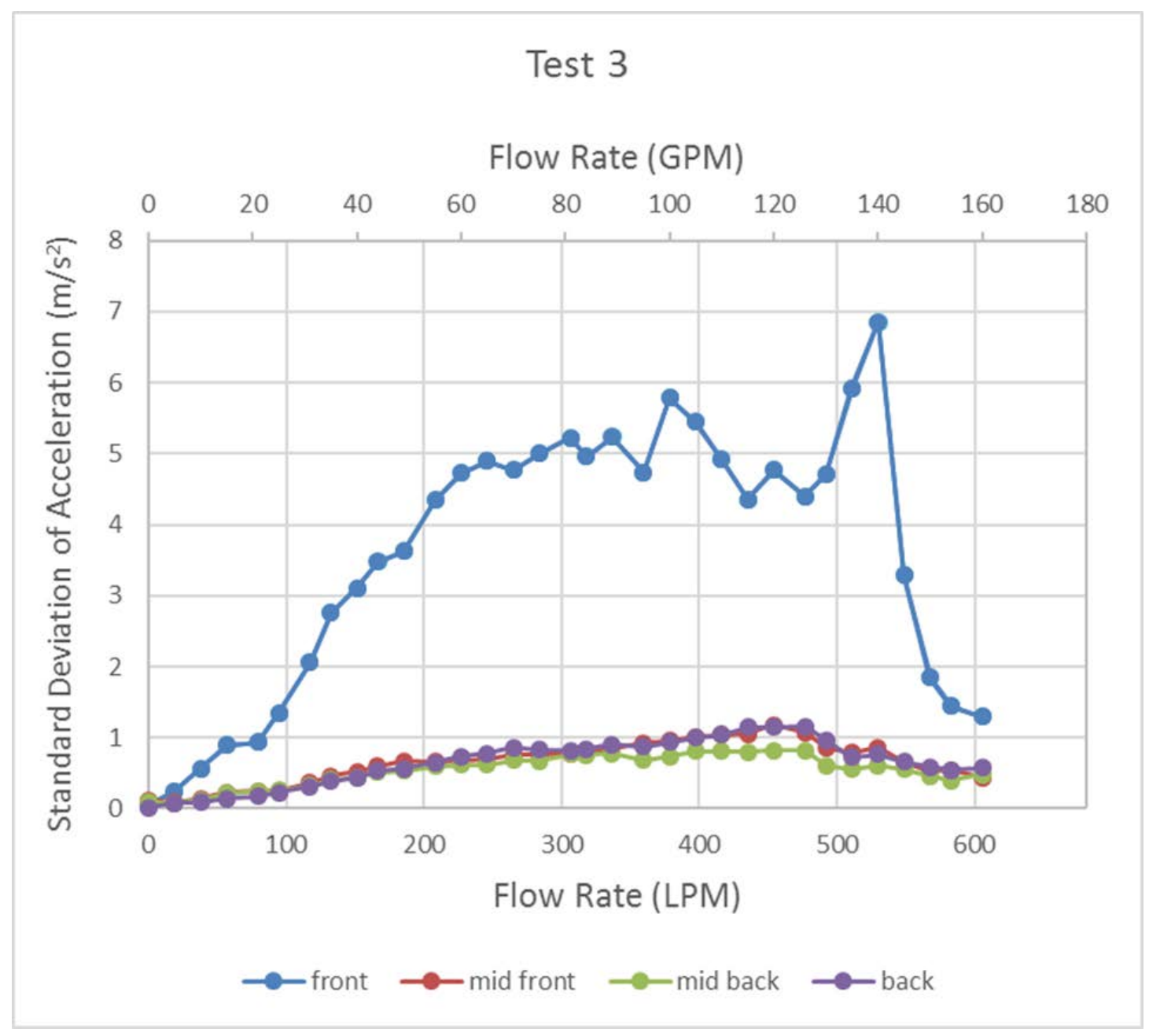

Fig. 24. Typical results of the standard deviation of acceleration versus flow rate for the four accelerometers in Test 3.

Based on previous studies using rigid pipe [13, 14, 16, 19-21], a decreasing trend was not expected at the higher flow rates for the flexible hose. The structural dynamic differences between the rigid pipes and the flexible hose could be causing the decreasing trend at higher flow rates, although additional research is needed for confirmation. The bell-shaped curve determined at each accelerometer location excludes the standard deviation of acceleration as a primary metric for determining flow rate over the entire flow rate range because of the lack of monotonicity; at a single level of standard deviation of acceleration, there could be two corresponding flow rates. 


\subsubsection{Results and Discussion - Wired Accelerometers Test 3 - Dominant Frequency}

The time-domain, acceleration data was converted to frequency-domain using a Fast Fourier Transform (FFT). A dominant frequency at each flow rate was observed (Fig. 11). A decreasing trend was observed for the front accelerometer, however not for the back, midback, and mid-front accelerometer locations (Fig. 25). When water is flowing through a rigid pipe, the dominant frequency typically does decrease with increasing flow rate $[13,15,18]$. Thus, a similar trend was expected for flexible hose.

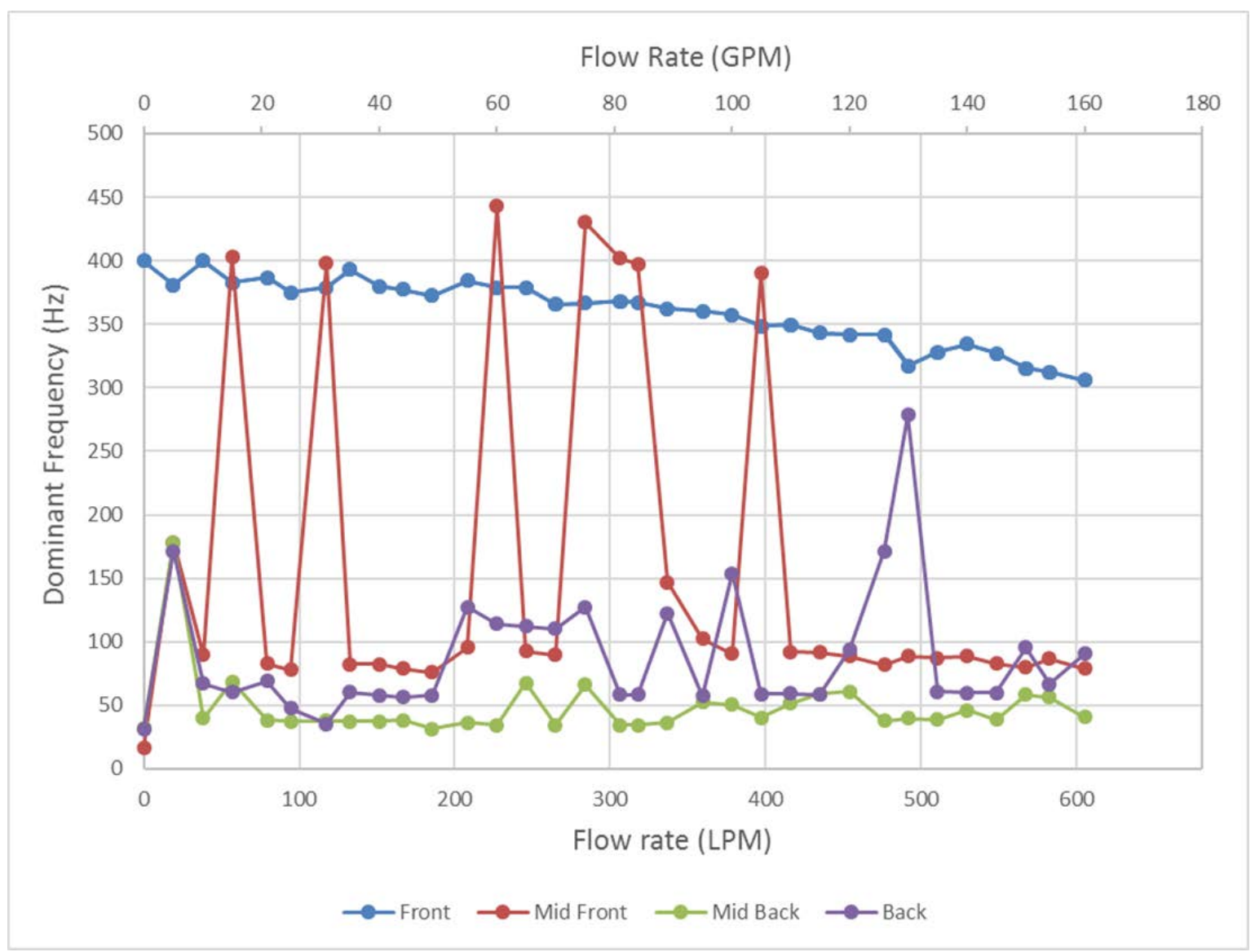

Fig. 25. Dominant frequency versus flow rate for all four accelerometers for Test 3.

The difference between the front accelerometer and the other locations for the dominant frequency results (Fig. 25) and the standard deviation of acceleration results (Fig. 24) may be due to the surface supporting the hose impacting the vibration dynamics. The front accelerometer was located on hose that was in grass, whereas the other accelerometers were located on hose supported by concrete. Additional research is needed to understand the source of these location-related differences.

Based on Fig. 25, further analysis was focused only on the front, downstream, accelerometer, closest to the nozzle. The mean of all 50 data collection increments for Test 3 are shown in Fig 26 with standard deviation bars. The dominant frequency decreased consistently with 
increasing flow rate as expected $[13,15,18]$. A dominant frequency value is not shown for 0 LPM because the signal noise instead of the hose flow dominated the signal. Based on the impact tests however, the dominant frequency at the no-flow condition was approximately $395 \mathrm{~Hz}$ (Fig. 27).

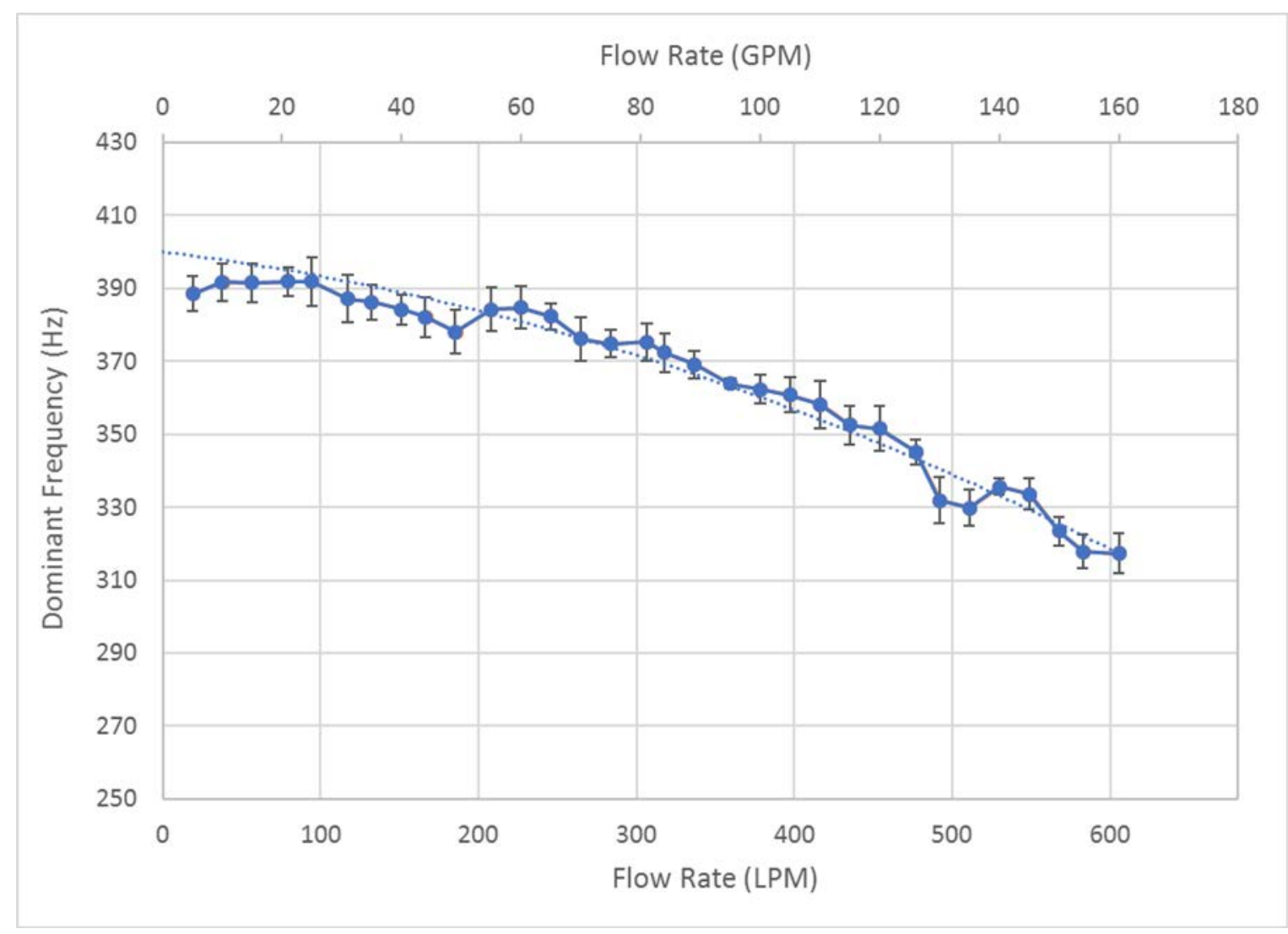

Fig. 26. The mean and standard deviation for the dominant frequency versus flow rate for the Front accelerometer for all 50 data collection increments for Test 3.

The impact tests were originally performed to understand the flexible hose dynamics as well as the dominant frequency of the hose system so that the standard deviation of acceleration analysis would not be influenced by the dominant frequency. After further analysis, the dominant frequency relationship with flow rate became the preferred metric, and the flow testing data was used to determine the dominant frequency. To confirm the analysis, we compared the results from two different testing approaches: impact testing and flow-rate testing.

The dominant-frequency results as calculated from the impact testing at 5 flow rates were very similar to the results from the flow tests (Fig. 27-28). The mean dominant frequency from the impact testing also decreased with increasing flow rate (Fig. 28). Six runs of the 30 collected were used to represent the entire data set (Fig. 27). 


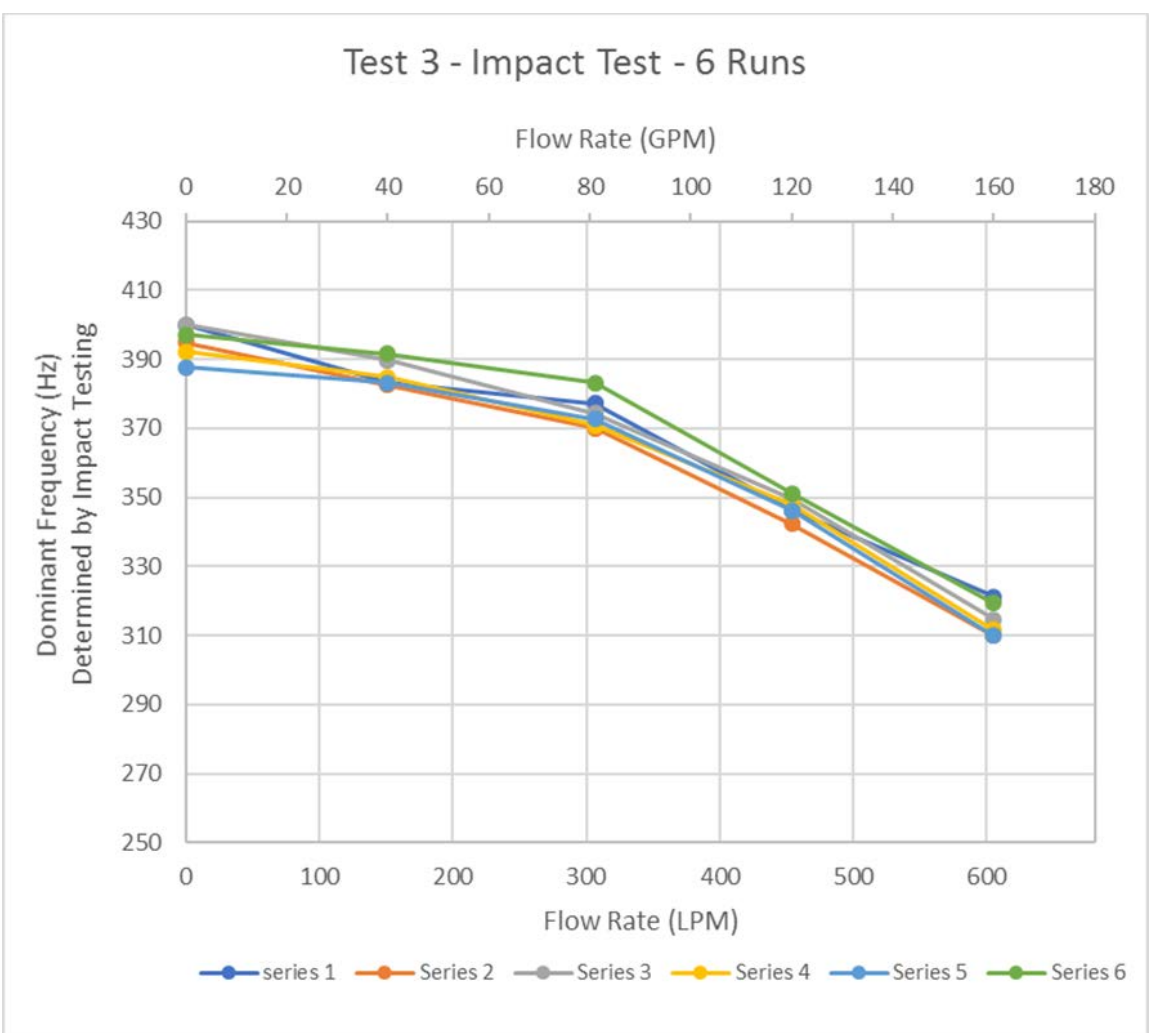

Fig. 27. Dominant frequency versus flow rate for the Front accelerometer for Test 3 as determined by impact testing.

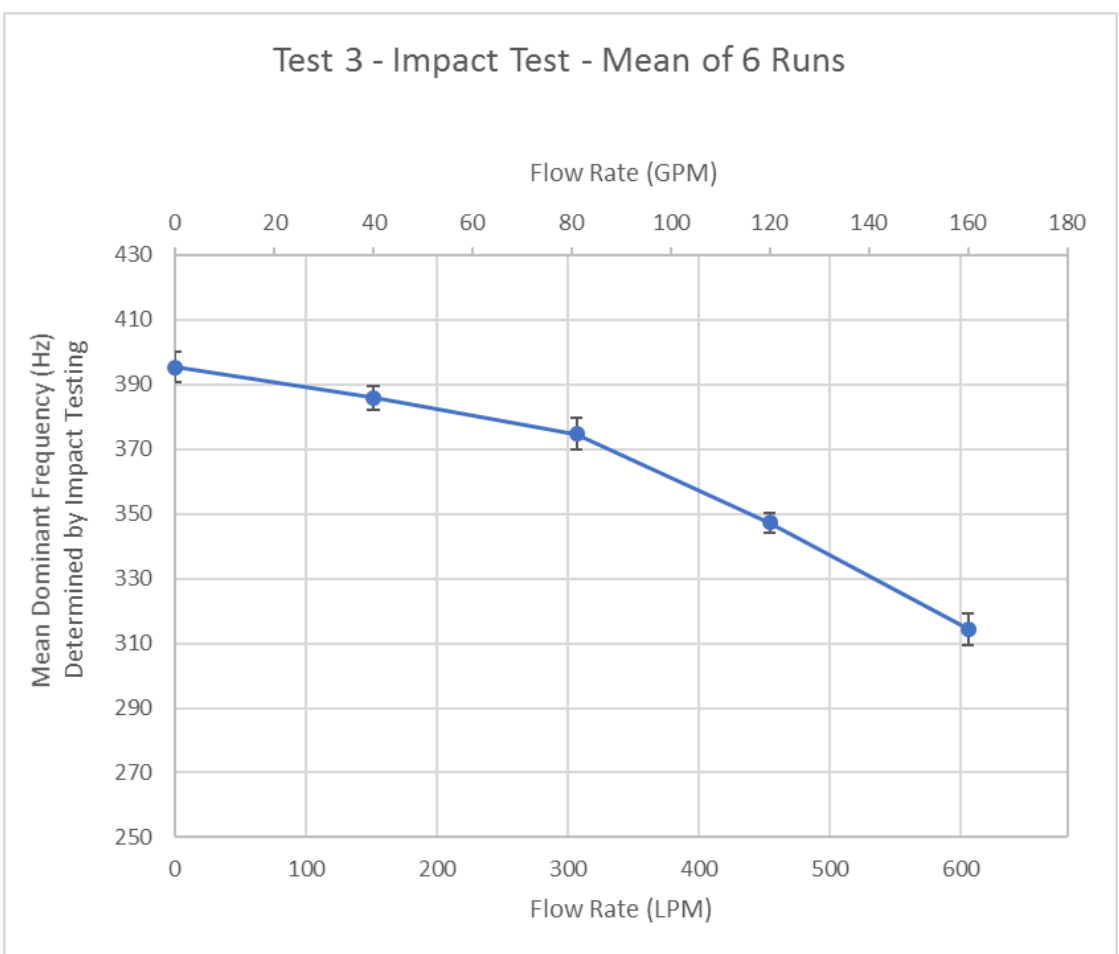

Fig. 28. Mean dominant frequency versus flow rate for the Front accelerometer for Test 3 as determined by impact testing. 
The comparison of the dominant frequency from both the impact testing (Fig 28) and the flow tests (Fig 26) showed very similar results. This comparison confirmed the determination of the dominant frequency using only the flow tests. No additional impact testing was therefore needed on any further tests, an important step towards determining real-time flow using dominant frequency as a metric since impact testing with a hammer will not be required.

Based on the front accelerometer results for the dominant frequency, determined both by the water flow testing and by impact testing, the dominant frequency metric was chosen as the main metric for application with the wireless accelerometer network for real-time flow rate, which will be the next step in this research [3]. One dominant frequency corresponds to a single flow rate.

\section{Practical Considerations for a Nozzle Flow Meter}

Having a small, lightweight, exterior flow meter at the nozzle of a fire hose to measure flow directly rather than hose water pressure has advantages for structural fire fighting as described earlier in this report. There are, however, limitations to the wired sensor network and these limitations will need to be resolved for the current flow meter to serve as a practical tool for the fire service. One limitation is the wires used by the accelerometer to communicate and receive power from the DAS. A practical version of this system will need to be able to communicate wirelessly to a base station or fire engine. Also, for the wireless system network, the accelerometer will need a source of power.

An additional limitation includes the ability of the current accelerometer to withstand high temperatures while exposed on the exterior fabric of the fire hose. Also, the current size of the accelerometer is a limitation. Although it is much smaller and lightweight compared to many typical commercial flow meters, the accelerometer still protrudes from the hose and could easily get damaged. Additional research will be necessary to further develop the accelerometers-based systems to withstand high temperatures and improve durability.

A flow meter at the fire hose nozzle could have additional benefits besides the application for structural fire fighting. Increased situational awareness regarding nozzle water flow could likewise benefit the fire service in extremely hazardous environments such as chemical, radiation, or explosive environments, where humans do not have sufficient protection. A flow meter at the hose nozzle of a charged hose line with a robot in these environments could provide feedback when beyond the IC's line of sight. A robot mounted camera may not be able to visually provide confirmation of water flow in smoky or dark conditions that block the camera from capturing images.

Situational awareness is also important for wildland fire fighting. Measuring water flow at many locations along a forestry hose would improve situational awareness where a forestry hose line may be stretched unattended and out of sight for hundreds of feet along a fire line. Typically, not all wildland fire fighters carry radios so communication with the engine pump operator could be difficult in rolling hills or forest. It is easy to consider that a wildland attack hose may develop a hose leak due to a puncture from ground debris or develop a burn hole from a spot fire or flying embers. A sensor at multiple nozzles or hose locations along 
the hose line could measure flow rate for the pump operator and improve situational awareness.

\section{Uncertainty}

There are several possible sources of uncertainty in this study, which must be considered. The commercial flowmeter specifications report a $\pm 1 \%$ accuracy over the flow range for the meter. This is consistent with the range of drift in the flow rates from the reference flow meter, mentioned earlier in this report, of approximately \pm 3.8 LPM (1.0 GPM) at the higher reference flow rates and less drift of approximately \pm 1.9 LPM (0.5 GPM) at lower reference flow rates. There is also a likely contribution of uncertainty in our measurements attributed to the fluctuation in the water flow from the water source; the water utility pipes of the building providing the pressured water supply to the fire hose. The uncertainty contribution from the water supply is likely to be a much larger contribution than the uncertainty from the accelerometers. The measurement uncertainty from the accelerometers, at the $95 \%$ confidence level with coverage factor of 2 , was estimated at less than $\pm 1.0 \%$ for the frequency range used in this study.

\section{Conclusion}

The overall goal of this study is to improve fireground situational awareness by developing a wireless sensor network to measure real-time water flow at the fire hose nozzle. Hose vibration data will be collected and then communicated wirelessly to a device where the data is converted into flow rate in real-time for improved situational awareness and efficient fireground decisions.

The focus of this first technical note was to use a wired piezoelectric accelerometer as a sensor to determine flow rate near the nozzle of a fire hose. The standard deviation of acceleration and dominant frequency were examined to determine which metric would correlate well with flow rate over the entire flow rate range. The dominant frequency metric yielded a somewhat linear and generally monotonic relationship with flow rate for an accelerometer located close to the hose nozzle that can be applied for further study.

The next step in this research, documented in a second NIST technical note [3], will be to develop the wired accelerometer system into a wireless sensor network and apply a metric based on dominant frequency and other measures to robustly determine water flow rate in a fire hose. The final step will be to use the wireless accelerometer network and finalized metric to determine real-time flow in a fire hose to improve fireground situational awareness.

\section{References}

[1] Petrillo AM (2019) Hoses: Large and Small, from LDH to Forestry Lines. Fire Apparatus and Emergency Equipment. June, 24(6). https://digital.fireapparatusmagazine.com/fireapparatus/june_2019/MobilePagedRepli ca.action?pm=2\&folio=16\#pg16 
[2] Hamins A, Grant C, Bryner N, Jones A, Koepke G (2015) Research Roadmap for Smart Fire Fighting, National Institute of Standards and Technology, Gaithersburg, MD, NIST Special Publication (SP) 1191. https://doi.org/10.6028/NIST.SP.1191

[3] Brown CU, Vogl GW, Tam WC (2019) Measuring Water Flow Rate for a Fire Hose Using a Wireless Sensor Network for Smart Fire Fighting. National Institute of Standards and Technology, Gaithersburg, MD, NIST Technical Note 2074. https://doi.org/10.6028/NIST.TN.2074

[4] Park G, Cudney HH, and Inman DJ (2001) Feasibility of using impedance-based damage assessment for pipeline structures. Earthquake Engineering and Structural Dynamics 30:1463-1474 (DOI: 10.1002/eqe.72)

[5] Kim Y, Schmid T, Charbiwala ZM, Friedman J, Srivastava MB (2008) NAWMS: nonintrusive autonomous water monitoring system, SenSys, Raleigh, NC.

[6] Urthaler Y, Luther EM, Breaux LE, Austin J, McNeill S, and Tognarelli M (2011) A methodology for assessment of internal flow-induced vibration (FIV) in subsea piping systems. Proceedings of the ASME 2011 30th International Conf. on Ocean, Offshore and Arctic Engineering, June 19-24, Rotterdam, The Netherlands.

[7] Owojaiye G, and Sun Y (2013) Focal design issues affecting the deployment of wireless sensor networks for pipeline monitoring. Ad Hoc Networks 11. https://doi.org/10.1016/j.adhoc.2012.09.006

[8] Nwalozie GC and Azubogu ACO (2014) Design and implementation of pipeline monitoring system using acceleration-based wireless sensor network. Int. Journal of Engineering and Science 3(9): 49-58.

[9] Yazdekhasti S, Pratla KR, Atamturktur S, Khan AA (2016) Novel vibration-based technique for detecting water pipeline leakage. Structure and Infrastructure Engineering. DOI: 10.1080/15732479.2016.1188318

[10] Mistretta L, Giaconia GC, Valenza A, Napoli E, Gianguzzi C, Presti ML, Puma FD (2018) Embedding Monitoring Systems for Cured-In-Place Pipes, A. De Gloria (ed.). Applications in Electronics Pervading Industry, Environment and Society, Lecture Notes in Electrical Engineering 429. DOI 10.1007/978-3-319-55071-8_2

[11] Clinch JM (1969) Measurements of the wall pressure field at the surface of a smoothwalled pipe containing turbulent water flow. J. Sound Vib 9(3): 398-419.

[12] Kim YK, and Kim YH (1996) A three accelerometer method for the measurement of flow rate in pipe. J. Acoustical Society of America, 100(2): 717-726.

DOI:10.1121/1.416211 
[13] Evans RP, Blotter JD, Stephens AG (2004) Flow rate measurements using flowinduced pipe vibration. Transactions of the ASME 126: 280-285. DOI: $10.1115 / 1.1667882$

[14] Pittard MT, Evans RP, Maynes RD, and Blotter JD (2004) Experimental and numerical investigation of turbulent flow induced pipe vibration in fully developed flow. Review of Science Instruments 75(7): 2393-2401. Doi: 10.1063/1.1763256

[15] Blevins RD (1977) Flow-Induced Vibration. Van Nostrand Reinhold Company, NY, pp 287-311.

[16] Thompson AS, Maynes D, and Blotter JD (2010) Internal turbulent flow induced pipe vibrations with and without baffle plates, Proceedings of the ASME 2010 3rd Joint US-European Fluids Engineering Summer Meeting and 8th International Conference on Nanochannels, Microchannels, and Minichannels. Aug 1-5, Montreal, Canada.

[17] Dinardo G, Fabbiano L, Vacca G (2013) Fluid flow rate estimation using acceleration sensors. Seventh Int. Conf. on Sensing Technology, pp. 221-5.

[18] Campagna MM, Dinardo G, Fabbiano L and Vacca G (2015) Fluid flow measurements by means of vibration monitoring. Meas. Sci. Technol. 26. DOI:10.1088/0957-0233/26/11/115306

[19] Medeiros KAR, Barbosa CRH, and Oliveira EC (2015) Flow measurement of piezoelectric accelerometers: application in the oil industry. Petroleum Science and Technology 33:1402-1409. DOI:10.1080/10916466.2015.1044613

[20] Medeiros KAR, Oliveira FLA, Barbosa CRH, and Oliveira EC (2016) Optimization of flow rate measurement using piezoelectric accelerometers: application in water industry. Measurement 91:576-581.

[21] Lannes DP, Gama AL, and Bento TFB (2018) Measurement of flow rate using straight pipes and pipe bends with integrated piezoelectric sensors. Flow Measurement and Instrumentation 60: 208-216.

[22] AS/NZS 1221:1997 Australian / New Zealand Standard Fire Hose Reels. 